\title{
Modified cell cycle status in a mouse model of altered neuronal vulnerability (slow Wallerian degeneration; WIds) Thomas M Wishart ${ }^{* \dagger}$, Helen N Pemberton ${ }^{\ddagger}$, Sally R James ${ }^{\ddagger}$, Chris J McCabe and Thomas H Gillingwater $^{*+}$
}

\begin{abstract}
Addresses: *Centre for Integrative Physiology, University of Edinburgh Medical School, Edinburgh, EH8 9XD, UK. ${ }^{\dagger}$ Centre for Neuroscience Research, University of Edinburgh Medical School, Edinburgh, EH8 9XD, UK. ₹Division of Medical Sciences, Institute of Biomedical Research, University of Birmingham, Birmingham, B15 2TH, UK.
\end{abstract}

Correspondence: Thomas H Gillingwater. Email: T.Gillingwater@ed.ac.uk

Published: 20 June 2008

Genome Biology 2008, 9:RIOI (doi:I0.I I86/gb-2008-9-6-r I0I)

The electronic version of this article is the complete one and can be found online at http://genomebiology.com/2008/9/6/RI0I
Received: 21 May 2008

Revised: 12 June 2008

Accepted: 20 June 2008

(C) 2008 Wishart et al.; licensee BioMed Central Ltd.

This is an open access article distributed under the terms of the Creative Commons Attribution License (http://creativecommons.org/licenses/by/2.0), which permits unrestricted use, distribution, and reproduction in any medium, provided the original work is properly cited.

\begin{abstract}
Background: Altered neuronal vulnerability underlies many diseases of the human nervous system, resulting in degeneration and loss of neurons. The neuroprotective slow Wallerian degeneration (W/ds) mutation delays degeneration in axonal and synaptic compartments of neurons following a wide range of traumatic and disease-inducing stimuli, providing a powerful experimental tool with which to investigate modulation of neuronal vulnerability. Although the mechanisms through which WIds confers neuroprotection remain unclear, a diverse range of downstream modifications, incorporating several genes/pathways, have been implicated. These include the following: elevated nicotinamide adenine dinucleotide (NAD) levels associated with nicotinamide mononucleotide adenylyltransferase I (Nmnat l; a part of the chimeric Wlds gene); altered mRNA expression levels of genes such as pituitary tumor transforming gene I (Pttgl); changes in the location/activity of the ubiquitin-proteasome machinery via binding to valosin-containing protein (VCP/p97); and modified synaptic expression of proteins such as ubiquitin-activating enzyme EI (Ubel).

Results: WIds expression in mouse cerebellum and HEK293 cells induced robust increases in a broad spectrum of cell cycle-related genes. Both NAD-dependent and PttgI-dependent pathways were responsible for mediating different subsets of these alterations, also incorporating changes in VCP/p97 localization and Ubel expression. Cell proliferation rates were not modified by WIds, suggesting that later mitotic phases of the cell cycle remained unaltered. We also demonstrate that WIds concurrently altered endogenous cell stress pathways.

Conclusion: We report a novel cellular phenotype in cells with altered neuronal vulnerability. We show that previous reports of diverse changes occurring downstream from WIds expression converge upon modifications in cell cycle status. These data suggest a strong correlation between modified cell cycle pathways and altered vulnerability of axonal and synaptic compartments in postmitotic, terminally differentiated neurons.
\end{abstract}




\section{Background}

Recent studies have highlighted the important role that vulnerability of nonsomatic neuronal compartments such as axons and synapses plays in the instigation and progression of neurodegenerative diseases, including Alzheimer's disease, multiple sclerosis, prion disease, Huntington's disease, and motor neuron diseases [1-4]. However, our understanding of the independent mechanisms that are required to regulate degenerative pathways in axons and synapses remains in its infancy. One powerful experimental tool that has already yielded novel insights into such pathways is the slow Wallerian degeneration $\left(W l d^{s}\right)$ mutation that selectively protects axons and synapses in the central and peripheral nervous systems following a wide variety of traumatic and diseaserelated, degeneration-inducing stimuli [5-12].

The $W l d^{s}$ mutation occurred spontaneously in a breeding colony of $\mathrm{C} 57 \mathrm{Bl} / 6$ mice, resulting in a tandem triplication of an 85 kilobase region on distal chromosome 4 [13]. The Wlds gene encodes a fusion protein that comprises the full length of nicotinamide mononucleotide adenylyltransferase 1 (Nmnat1; a nicotinamide adenine dinucleotide [NAD $\left.{ }^{+}\right]$synthesizing enzyme), coupled by a unique 18-amino-acid sequence to the amino-terminal 70 amino acids of the ubiquitination enzyme ubiquitination factor E4B (Ube4b) [14]. Transgenic expression of the $W l d^{s}$ gene is sufficient to confer the full neuroprotective phenotype in several species, including mice, rats, and Drosophila [14-16]. Despite providing substantial protection for axons and synapses, cell bodies are not protected in $W^{\prime} d^{s}$ mice [17-19].

The Wlds protein product appears to be localized exclusively to neuronal nuclei, suggesting that it confers its neuroprotective effects indirectly via modification of endogenous cellular pathways [14,20-22], but there remains considerable controversy over which cellular pathways may need to be targeted to confer $W l d^{s}$-mediated neuroprotection. For example, several studies have demonstrated that the NAD/Sirt1 pathway can modulate axonal degeneration as a result of increased NAD levels, driven by Nmnat1 in the chimeric $W l d^{s}$ gene [23-25]. However, NAD pathways alone are insufficient to confer the full neuroprotective phenotype in vivo [26,27]. Other studies have suggested that modifications of the ubiquitin-proteasome system are required for neuroprotection, in part because of the ability of $W l d^{s}$ to bind valosin-containing protein (VCP/ p97) $[28,29]$. Genomic and proteomic studies have identified other downstream effects of $W l d^{s}$ expression in vivo and in vitro. For example, array experiments have revealed modified expression levels for a range of genes, including the robust downregulation of mRNA encoding pituitary tumor transforming gene 1 (Pttg1 [22,30]). Similarly, proteomic experiments have demonstrated modifications in the levels of mitochondrial and/or synaptic proteins such as ubiquitinactivating enzyme E1 (Ube1) [31]. However, a unified hypothesis that brings together these distinct observations is currently lacking.
We made the previously unrecognized observation that many of these downstream changes also influence cell cycle. For example, Pttg1 is an oncogene with a recently established role in regulating the $G_{1}$ to $S$ phase transition of cell cycle [32]. Similarly, Ube1 is a protein with well established roles in cell cycle [33-36], and VCP/p97 localization is intricately linked to the cell cycle, with nuclear localization only occurring during late $G_{1}$ phase [37]. In addition, several studies have demonstrated that NAD-dependent pathways play important roles in regulating cell cycle [38-40]. Taken together with numerous published studies reporting that cell cycle status can play an important role in modulating neuronal vulnerability and neurodegenerative pathways [41-49], these observations suggest that cell cycle modulation may provide a unified, common pathway on which genetic and proteomic changes downstream of $W l d^{s}$ may act to confer neuroprotection.

Here we show that $W l d^{s}$ expression in both mouse cerebellum in vivo and in HEK293 cells in vitro leads to robust increases in expression of a broad spectrum of cell cycle related genes, indicative of an attempt to re-enter cell cycle. We also provide evidence that these cell cycle changes involve all of the $W l d^{s}$ mediated pathways detailed above (Pttg1, Ube1, NAD, and VCP), pushing postmitotic, terminally differentiated neurons toward cell cycle re-entry without affecting later mitotic phases. These data have identified a novel cellular phenotype in $W l d^{s}$-expressing cells, unifying several diverse observations to reveal modifications in cell cycle status with concurrent alterations in cell stress. We propose that there exists a strong correlation between modified cell cycle pathways and altered vulnerability of axonal and synaptic compartments in postmitotic, terminally differentiated neurons.

\section{Results \\ Increased expression of cell cycle genes and proteins in WIds-expressing cells in vivo and in vitro}

We used cell cycle pathway-specific RT ${ }^{2}$ profiler PCR arrays (see Materials and methods [below]) to quantify and compare the expression of cell cycle-related genes with high sensitivity. Initially, we used RNA extracted from the cerebellum of wildtype and $W l d^{s}$ mice because this tissue has proven ideal for comparative genomic experiments [22]. Wlds cerebellar granule cells are also known to express Wlds protein at high levels and exhibit a strong neuroprotective phenotype [22]. We compared expression levels of 84 genes that regulate the cell cycle, including transitions between each of the phases, DNA replication, checkpoints, and arrest. Seventeen out of the 84 genes examined (around 20\%) had expression levels increased by more than twofold in Wlds cerebellum (Figure 1 and Table 1). The array identified changes in genes associated with many different stages of the cell cycle rather than one specific stage (Table 1). Interestingly, no cell cycle related genes appeared to be suppressed greater than twofold by Wlds (Figure 1 and Table 1 ). 


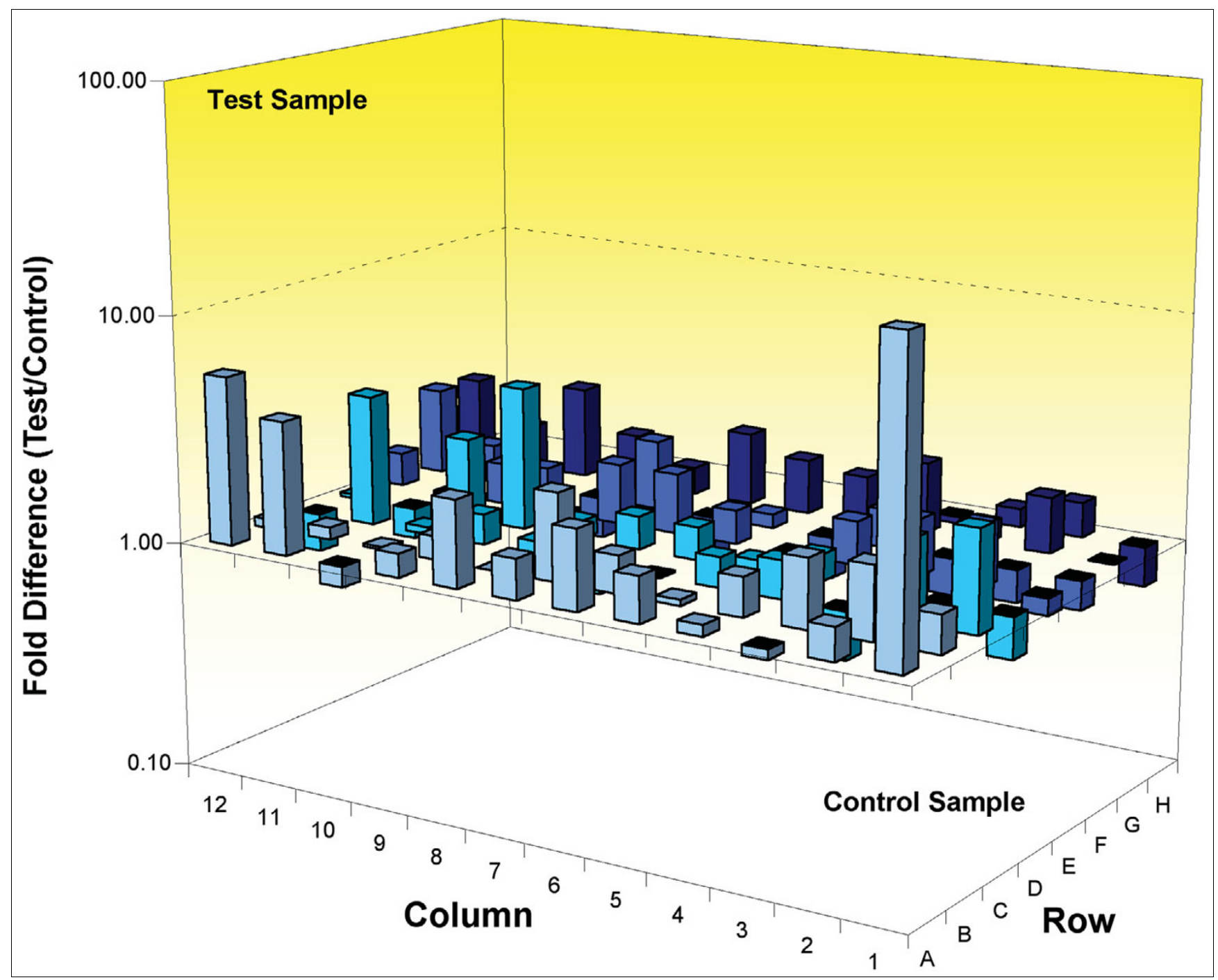

Figure I

Up-regulation of cell cycle genes in terminally differentiated neurons from WIds mouse cerebellum in vivo. Three-dimensional bar chart taken from SuperArray analysis software (cell cycle specific SuperArray; see Materials and methods) showing fold difference in expression levels for 84 cell cycle related genes, comparing wild-type cerebellum (control sample) with WIds cerebellum (test sample). Individual genes with greater than twofold expression change can be found in Table I.

To confirm that RNA changes led to corresponding changes in protein levels, we quantified protein expression levels in the cerebellum of $W l d^{s}$ and wild-type mice in vivo. We chose to focus on one of the genes with a large RNA change and one with a smaller change, just above the twofold threshold, where good antibodies were available (cABL and Brca2, respectively; Table 1). The protein product for both of these genes exhibited corresponding increased expression levels, of a similar ratio to that seen for RNA (Figure 2). In addition, we examined protein levels of other known cell cycle regulators to show that the changes observed on the PCR arrays were not exclusive. Three of the four additional proteins examined (histone $\mathrm{H} 2 \mathrm{~B}, \mathrm{BRCA} 1$, and phosphohistone $\mathrm{H} 2 \mathrm{Ax}$ ) exhibited significantly increased expression levels in $W l d^{s}$ cerebellum, which is in keeping with the general trend observed on the PCR arrays (Figure 2).

Next, we established that protein levels of two other cell cycle regulators, not included on the PCR array chip but previously shown to be modified in $W l d^{s}$ neurons, were similarly altered. Previous studies have demonstrated that protein levels of Ube1 (a protein with known cell cycle involvement [33-36]) are increased in $W^{\prime} d^{s}$ synapses [31], and we were able to confirm this finding by showing increased total Ube1 protein levels in $W l d^{s}$ cerebellum (Figure 2). In addition, immunocytochemical staining for Ube1 confirmed increased nuclear expression levels in $W l d^{s}$-expressing neurons in vivo (Figure 3). We also found that Pttg1 protein levels (another 
Table I

\begin{tabular}{|c|c|c|c|c|c|c|}
\hline Gene name & Symbol & Acc. Number & Array cell & Fold change & SD & Cell cycle function \\
\hline V-abl Abelson murine leukemia oncogene I & $A b l l$ & NM 009594 & $\mathrm{AOI}$ & 21.91 & 1.74 & Regulation \\
\hline Cyclin BI & Ccnbl & NM 17230I & $\mathrm{A} / 2$ & 5.50 & 0.65 & M phase and regulation \\
\hline $\begin{array}{l}\text { Antigen identified by monoclonal antibody } \\
\text { Ki } 67\end{array}$ & Mki67 & $\underline{X M \quad 133912}$ & D09 & 4.23 & 0.41 & $S$ phase and DNA replication \\
\hline Cyclin A2 & Ccna2 & NM 009828 & All & 3.85 & 0.65 & Regulation \\
\hline G protein-coupled receptor 132 & Gprl32 & NM 019925 & $\mathrm{CII}$ & 3.73 & 0.82 & $\mathrm{G}_{1}$ phase and $\mathrm{G}_{1} / \mathrm{S}$ transition \\
\hline Checkpoint kinase I homolog & Chekl & NM 007691 & $\mathrm{COI}$ & 2.74 & 0.81 & $\mathrm{G}_{2}$ phase and $\mathrm{G}_{2} / \mathrm{M}$ transition \\
\hline Transformation related protein 63 & Trp63 & NM 011641 & GIO & 2.53 & 0.06 & Negative regulator \\
\hline Cyclin-dependent kinase 2 & Cdk2 & NM 016756 & B07 & 2.43 & 0.52 & M phase \\
\hline $\begin{array}{l}\text { Calcium/calmodulin-dependent protein } \\
\text { kinase II, beta }\end{array}$ & Camk2b & NM 007595 & A08 & 2.41 & 0.10 & $G_{\mid}$phase and $G_{1} / S$ transition \\
\hline S-phase kinase-associated protein $2(\mathrm{p} 45)$ & Skp2 & NM 013787 & $\mathrm{FI} 2$ & 2.40 & 0.26 & $\begin{array}{l}G_{1} \text { phase and } G_{1} / S \text { transition and } \\
\text { regulation }\end{array}$ \\
\hline Wee I homolog & Weel & NM 009516 & $\mathrm{G} 12$ & 2.33 & 0.02 & M phase \\
\hline Meiotic recombination II homolog A & Mrel la & NM 018736 & DIO & 2.28 & 0.57 & S phase and DNA replication \\
\hline $\mathrm{CDC} 28$ protein kinase $\mathrm{Ib}$ & $C k s / b$ & NM 016904 & $\mathrm{C} 02$ & 2.23 & 0.49 & Checkpoint and arrest and regulation \\
\hline Breast cancer 2 & Brca2 & NM 009765 & $\mathrm{~A} 06$ & 2.23 & 0.63 & $\begin{array}{l}M \text { phase and regulation and checkpoint } \\
\text { and arrest }\end{array}$ \\
\hline Cyclin C & Conc & NM_016746 & B02 & 2.07 & 0.12 & regulation \\
\hline Transcription factor Dp I & $T f d p l$ & NM 009361 & G07 & 2.07 & 0.06 & Regulation \\
\hline SMT3 suppressor of mif two 3 homolog I & Sumol & NM 009460 & G04 & 2.04 & 0.13 & S phase and DNA replication \\
\hline Retinoblastoma-like 2 & $R b / 2$ & NM 011250 & F08 & 2.01 & 0.25 & Negative regulator \\
\hline
\end{tabular}

$\mathrm{SD}$, standard deviation.

protein that regulates cell cycle pathways [32]) were significantly increased in $W l d^{s}$ cerebellum (Figure 2), which is in keeping with changes in all other cell cycle regulators modified by $W l d^{s}$. This result was surprising because although Pttg1 protein levels had not previously been examined in $W l d^{s}$-expressing cells, several previous reports have identified reduced mRNA levels for Pttg1 [22,30].

To verify that the alterations in cell cycle gene expression were occurring as a direct result of the presence of $W l d^{s}$, and to further confirm that RNA changes observed in $W l d^{s}$ mouse cerebellum led to corresponding changes in protein levels, we examined the effects of $W l d^{s}$ on cell cycle in human embryonic kidney (HEK293) cells after transfection with enhanced green fluorescent protein (eGFP)-tagged $W l d^{s}$ constructs [22]. We selected HEK293 cells for our experiments for two main reasons. First, we wanted to consider whether the expression changes observed in mouse neurons in vivo could be replicated in a human cell line, as has previously been demonstrated for other Wlds-mediated changes in gene expression [22]. Second, HEK293 cells are an experimentally amenable, homogenous cell line that is routinely used to study transcriptional effects $[22,50]$ and to model degenerative mechanisms in the human nervous system [51,52].

As for the cerebellar experiments, we again chose initially to focus on one gene with a large RNA change (Abl1) and one with a change just above the twofold threshold (Brca2). The protein product for both of these genes exhibited corresponding increased expression levels, of a similar ratio to that seen for RNA (Figure 4). In addition, we once again examined protein levels of other known cell cycle regulators to show that the changes observed on the PCR arrays were not exclusive. All four additional proteins examined (HDAC2, histone $\mathrm{H} 2 \mathrm{~B}$, acetyl histone $\mathrm{H}_{3}$, and phosphohistone $\mathrm{H}_{2} \mathrm{Ax}$ ) showed increased expression levels in $W l d^{s}$-transfected cells, which is in keeping with the general trend observed on the PCR arrays (Figure 1). These experiments also provided further confirmation that both Ube1 and Pttg1 protein levels are increased by $W l d^{s}$ expression (Figure 4; compare with Figures 2 and 3 ).

Because the Wlds protein is known to have a predominantly nuclear distribution [20,21], and most cell cycle proteins modulate cell cycle via interactions in the nucleus, we next tested whether $W l d^{s}$ expression altered the nuclear expression of cell cycle proteins. We chose to investigate the nuclear distribution of phosphohistone $\mathrm{H} 2 \mathrm{Ax}$ in Wlds-transfected HEK293 cells because this protein has a well-established role in the cell cycle [53,54] and was among the largest protein changes identified in HEK293 cells (Figure 5; see Figures 2 and 4 for phosphohistone H2Ax protein levels in vivo and in vitro). Not all cells express $W l d^{s}$ using our transfection protocol, as identified by the presence of an eGFP signal (Figure $5 \mathrm{~b}, \mathrm{e})$. We were therefore able to compare directly 


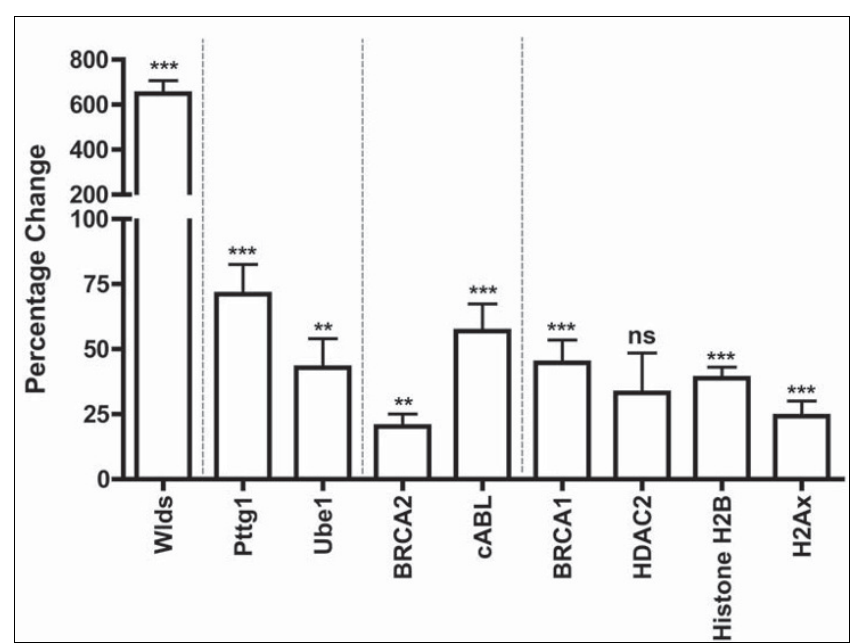

Figure 2

Quantitative fluorescent Western blots validate changes in cell cycle proteins in WIds cerebellum in vivo. Bar chart showing percentage change in protein expression (mean \pm standard error of the mean; $n \geq 3$ for all proteins) in WIds cerebellum compared with wild-type. As expected, WIds protein expression was highly upregulated (left bar). The second portion of the graph shows increases in both pituitary tumor transforming gene I (Pttgl) and ubiquitin-activating enzyme El (Ubel) proteins in Wlds mice, both of which have previously been implicated in the WIds neuroprotective phenotype [22,3I]. The third portion of the graph shows validation for two genes highlighted on the SuperArray analysis as being upregulated by more than twofold. The final portion of the graph shows similar increases in cell cycle proteins not included on the SuperArray plate, showing that increased expression of cell cycle proteins is not restricted to those included on the SuperArray. Statistical tests were carried out comparing raw expression data from wild-type mice with those from WIds mice. $* * p<$ $0.01, P<0.00$ I by unpaired $t$-test (two-tailed). ns, not significant.

experimental cells expressing $W l d^{s}$ or eGFP-only controls with neighbouring nontransfected cells. Anti-phosphohistone H2Ax antibodies revealed intense nuclear spots of phosphohistone H2Ax in all cells expressing Wlds (Figure $5 \mathrm{a}-\mathrm{f}$ ). However, neighbouring cells not expressing $W l d^{s}$ did not show any phosphohistone H2Ax nuclear puncta. No phosphohistone H2Ax staining was observed in control cells transfected with eGFP, indicating that the response was not simply the result of a large accumulation of foreign protein in the nucleus (Figure 5g-i).

Because we had found that a broad spectrum of cell cycle genes and proteins were modified by Wlds (Table 1), we next tested whether $W l d^{s}$ can influence neurons to pass through the complete cell cycle by quantifying proliferation rates in a human neuronal cell line (NT2 cells) using an MTT (3-[4,5dimethylthiazolyl-2]-2,5-diphenyltetrazolium bromide) assay. Introduction of a Wlds construct into NT2 cells did not modify cell proliferation rates compared with vector-only transfected cells, either at 48 or 72 hours after transfection, or at low, medium, or high doses (Figure 6a-b). These findings were confirmed using tritiated thymidine uptake assays where values were normalized to low dose treatment (mean count: $14,770 \pm 1,259$ disintegrations per minute [DPM]; Fig- ure $6 \mathrm{c}$ ). Tritiated thymidine uptake assays were performed at 48 hours post-transfection in order to corroborate data from MTT assays generated at the same experimental time point and because this was the time point anticipated to give the maximum chance of detecting a proliferative change in these cells. These data suggest that $W l d^{s}$ upregulates the expression of a broad range of cell cycle regulators, pushing cells toward cell cycle re-entry, but that pathways influencing later stages of the cycle, such as mitotic cell division, remain inhibited.

In order to confirm that $W l d^{s}$-mediated changes in cell cycle genes/proteins were pushing terminally differentiated neurons toward cell cycle re-entry rather than inhibiting cell cycle activation, we compared the profile of $W l d^{s}$-mediated protein changes with changes induced by a well known pharmacologic inhibitor of the cell cycle: the cyclin-dependent kinase inhibitor flavopiridol. Treatment of HEK293 cells with flavopiridol at an established active concentration $(10 \mu \mathrm{mol} / \mathrm{l}$ [48]) resulted in suppression of six out of eight cell cycle proteins that were increased in Wlds-transfected HEK293 cells (Figure 7). Thus, pharmacologic inhibition of the cell cycle also induced changes in cell cycle proteins known to be altered by $W l d^{s}$, but importantly these changes in expression levels occurred in the opposite direction. These data confirmed that $W l d^{s}$ reactivates dormant cell cycle pathways, pushing cells toward cell cycle re-entry rather than inhibiting it.

\section{Role of Pttg I, NAD, and VCP pathways in mediating cell cycle modulation}

After demonstrating that the $W l d^{s}$ gene robustly modifies cell cycle status in a variety of cell types in vivo and in vitro, we next investigated whether any of the previously identified downstream modifications induced by $W l d^{s}$ play a role in mediating cell cycle changes. First we investigated whether Pttg1 alone, as a known regulator of $G_{1}$ to $S$ phase cell cycle transition [32] with increased protein levels in Wlds-expressing cells (see Figures 2 and 4), was capable of mediating Wldsinduced effects on cell cycle proteins. We compared expression levels of four previously highlighted cell cycle proteins following transfection of HEK293 cells with either a Wlds construct [22] or a Pttg1 over-expression construct [55] (Figure 8a). Three of the four proteins examined were not modified by Pttg1 expression alone (Figure 8a), suggesting that other pathways are also required to induce the full range of cell cycle related changes (see below). However, Ube1 upregulation was induced by Pttg1 over-expression to a similar extent as seen with $W l d^{s}$. This suggests that elevated Ube1 protein levels previously reported in $W l d^{s}$ synapses [31] are occurring downstream from increases in Pttg1 protein levels.

Pttg1 is currently the only known physiological substrate for the E4 ubiquitination factor Ube $4 \mathrm{~b}$ [56], which is one of the constituent parts of the chimeric Wld ${ }^{s}$ gene [13]. In order to establish whether the ability of Pttg1 to be ubiquitinated is important for the regulation of Ube1, we repeated the 

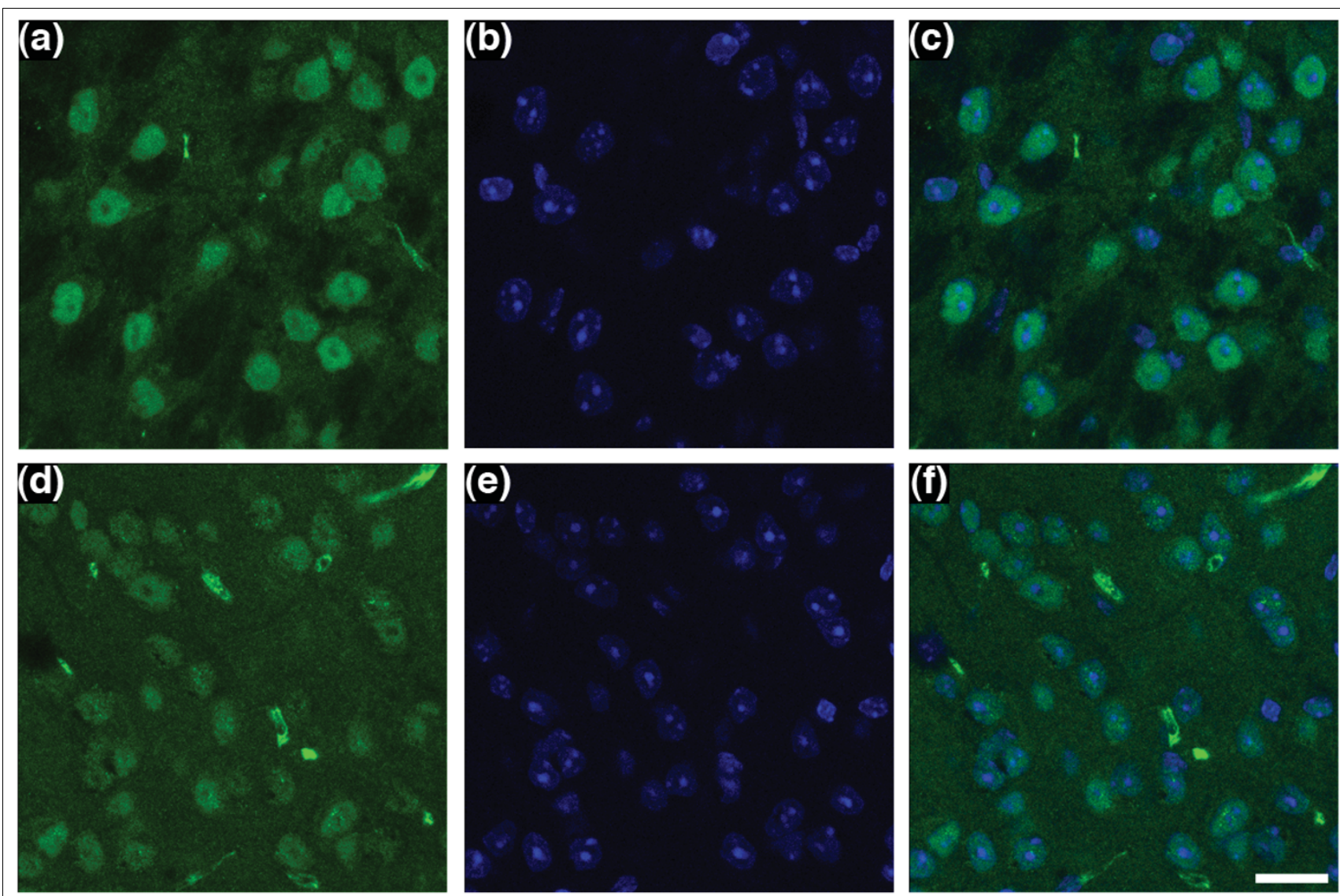

\section{(g)}

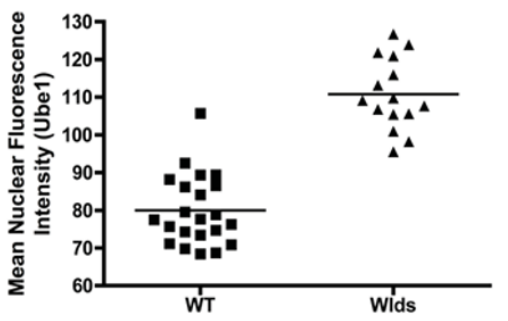

(h)

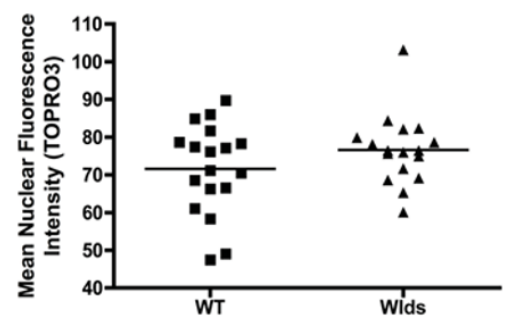

(i)

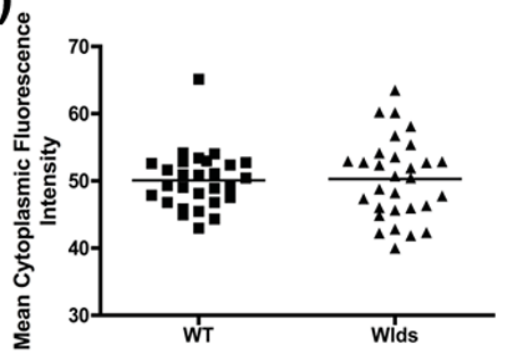

\section{Figure 3}

Immunocytochemistry confirms increased nuclear expression of Ubel in WIds mouse cerebellum. Confocal micrographs of cerebellar granule cells from (a-c) WIds and (d-f) wild-type mice. Ubiquitin-activating enzyme EI (Ubel) is shown in green and the nuclear marker TOPRO3 is shown in blue (panels a and $d$ show Ubel; panels b and e show TOPRO3; and panels $\mathrm{c}$ and $\mathrm{f}$ show both markers). Note how Ubel protein appears to be more strongly expressed in the nuclei of WIds cerebellar neurons, whereas TOPRO3 and cytoplasmic levels of Ubel appear unchanged. (g-i) Scatter plots (line indicates mean) of fluorescence intensity (see Materials and methods) of nuclear Ubel (panel g), nuclear TOPRO3 (panel h), and cytoplasmic Ubel (panel i). Only nuclear Ubel was significantly increased in intensity in WIds neurons $(P<0.001$; by unpaired, two-tailed $t$-test). Scale bar $20 \mu \mathrm{m}$.

experiment using an over-expression construct containing a non-ubiquitinatable form of Pttg1 [57]. The inability to be ubiquitinated completely abolished the ability of Pttg1 to increase Ube1 protein levels (Figure 8b), showing that ubiquitination of Pttg1 by Ube $4 b$ (and/or other proteins in the ubiquitin pathway) is likely to be important for $W l d^{s}$-mediated cell cycle changes.

Next, we investigated whether NAD-dependent pathways play a role in mediating cell cycle changes, because several recent studies have suggested that the Nmnat1 portion of the chimeric $W l d^{s}$ gene plays a significant role in conferring a neuroprotective phenotype by elevating NAD levels and increasing sirtuin activity [23-25]. To examine whether NAD pathways influence cell cycle changes observed in Wldsexpressing cells, we performed cell cycle pathway specific RT2 profiler PCR arrays (using human rather than mouse arrays; see Materials and methods [below]) on HEK293 cells treated with $1 \mathrm{mmol} / \mathrm{l} \mathrm{NAD}$ applied exogenously to the culture medium. This NAD treatment has previously been shown to 


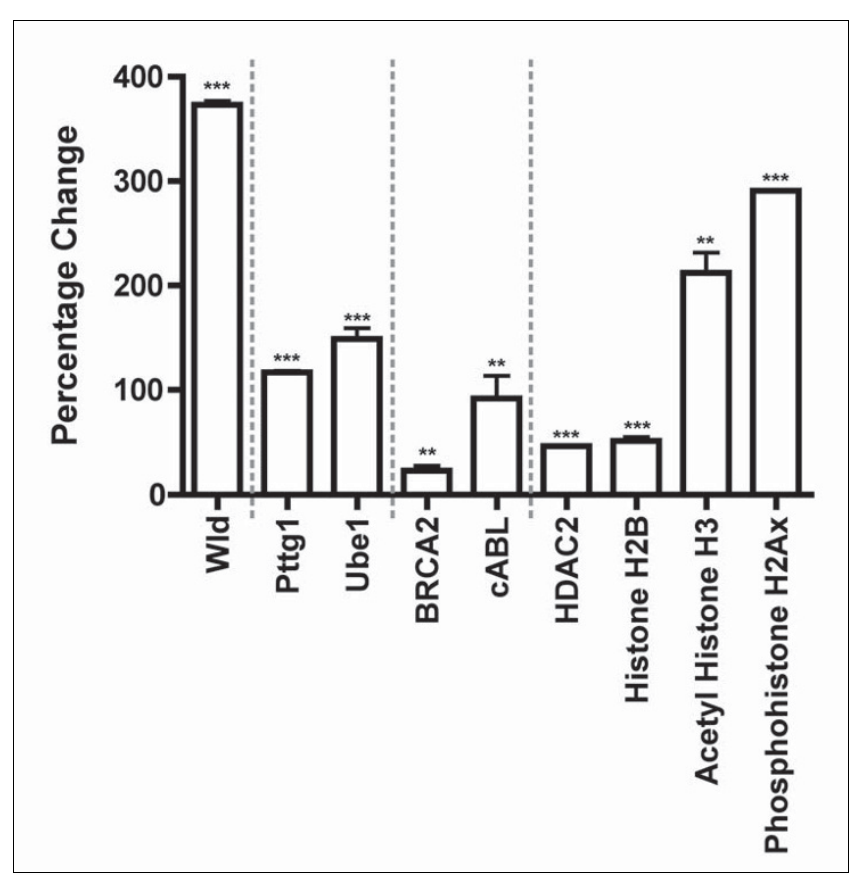

Figure 4

Quantitative fluorescent Western blots validate changes in cell cycle proteins in WIds-expressing HEK293 cells in vitro. Bar chart showing percentage change in protein expression (mean \pm standard error of the mean; $n \geq 3$ for all proteins) in WIds-transfected HEK293 cells compared with enhanced green fluorescent protein (eGFP)-transfected control cells. As expected, Wlds protein expression was highly upregulated (left bar). The second portion of the graph shows increases in both pituitary tumor transforming gene I (Pttgl) and ubiquitin-activating enzyme EI (Ubel) proteins following WIds transfection, both of which were previously implicated in the WIds neuroprotective phenotype [22,3I]. The third portion of the graph shows validation for two genes highlighted on the SuperArray analysis as being upregulated by more than twofold. The final portion of the graph shows similar increases in cell cycle proteins not included on the SuperArray plate, showing that increased expression of cell cycle proteins is not restricted to those included on the SuperArray. All genes were significantly increased in expression levels in WIdstransfected cells compared with control cells. $* * P<0.0$ I, $* * * P<0.00$ I by unpaired $t$-test (two-tailed).

confer axonal protection in vitro [23] and to mediate selected $W l d^{s}$-induced transcriptional changes [22]. Forty-eight out of the 84 genes examined exhibited greater than twofold changes in expression after NAD treatment. In a similar result to that obtained in the Wlds mouse cerebellar array experiments, the vast majority (47 out of the 84 ) of modified genes had increased expression levels in the NAD treated cells (Figure 9 and Table 2). Only one cell cycle related gene appeared to be suppressed greater than twofold by NAD (Figure 9). A direct comparison of SuperArray data from $W l d^{s}$ cerebellum and NAD-treated HEK293 cells showed changes of a similar magnitude for eight out of the nine genes examined (Figure 10a; only nine candidate genes could be directly compared due to their presence/alteration on both arrays). Increases in protein expression levels of Pttg1, BRCA2, BRCA1, and H2Ax in NSC34 cells treated with 1 mmol/l NAD for 4 days confirmed that these NAD-induced changes extend beyond those included on the SuperArray, extend to the protein level, and can occur in neuronal cells (Figure 10b). These data suggest that elevated exogenous NAD levels can mimic many, but importantly not all, Wlds-induced cell cycle changes.

Alongside identified changes in Pttg1/Ube1 expression and NAD pathways, previous studies have implicated VCP-mediated pathways (also known as p97 and CDC48) in $W l d^{s}$-mediated neuroprotection, via its interaction with the Ube $4 \mathrm{~b}$ component of the Wlds chimeric protein [28]. Moreover, VCP is known to be important in early stages of cell cycle progression; VCP is normally localised in the endoplasmic reticulum during nonproliferative states (for example, terminally differentiated neurons), but relocates to the nucleus during late $\mathrm{G}_{1}$ phase in a cell cycle dependent manner [37]. Thus, VCP localisation would not normally be observed in the nucleus of terminally differentiated neurons unless cell cycle had been reactivated and they are progressing toward $\mathrm{S}$ phase. To examine whether VCP redistribution associated with modified cell cycle status is modified by $W l d^{s}$, we examined VCP localization in the cerebellum of $W l d^{s}$ and wild-type mice. These experiments revealed an expected cytoplasmic, nonnuclear localization in wild-type neurons, but distinct, strong nuclear puncta in most cerebellar granule cells in $W l d^{s}$ mice (Figure 11). As predicted from the finding that VCP binds Wlds [28], VCP localization in the nucleus was consistently found in the same nuclear puncta as Wlds protein (Figure 11). These data provide further evidence that $W l d^{s}$-expressing cells are being pushed toward the early phases of cell cycle reentry and suggest that VCP binding may play a role in this process.

Thus, Pttg1/Ube1, NAD, and VCP pathways are all likely to be involved in mediating $W l d^{s}$-induced modifications in cell cycle status. Taken together, these findings suggest that previous observations of apparently unrelated changes in gene and protein expression/activity downstream of $W l d^{s}$ can in fact be unified by their ability to modify the cell cycle.

\section{Modifications in cell stress pathways induced by WIds in vivo and in vitro}

Changes in cell cycle status in terminally differentiated neurons are often associated with corresponding changes in cell stress pathways [58-6o]. To examine whether cell stress pathways were also altered in $W l d^{s}$-expressing cells, we used cell stress pathway-specific RT2 profiler PCR arrays (see Materials and methods [below]) to compare mRNA levels in the cerebellum of wild-type and $W l d^{s}$ mice (Figure 12). Fourteen out of the 84 genes contained on the array were modified greater than twofold by $W l d^{s}$, showing that a subset of cell stress pathways are also modified in $W l d^{s}$ (Figure 12 and Table 3). In contrast to the results from cell cycle arrays, however, Wlds neurons revealed both increases and decreases across a range of different cell stress proteins. 


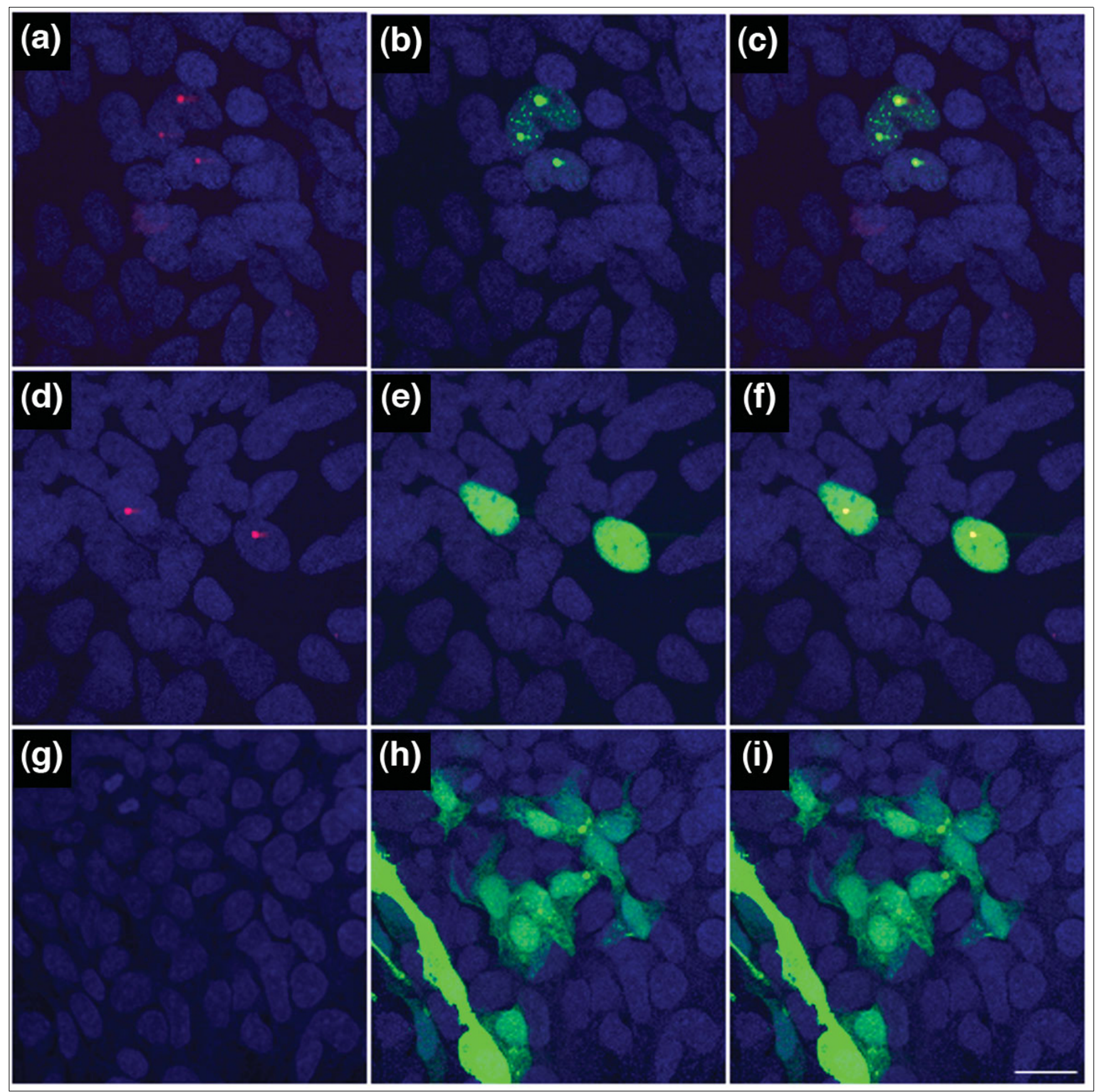

\section{Figure 5}

Increased expression of the cell cycle marker phosphohistone H2Ax in WIds transfected HEK293 cells. Confocal micrographs of HEK293 cells 5 days after transfection with either an (a-f) enhanced green fluorescent protein (eGFP)-WIds construct or ( $g$-i) a eGFP-only control construct. Immunocytochemical labeling of phosphohistone $\mathrm{H} 2 \mathrm{Ax}$ is shown in red, the nuclear marker TOPRO3 is shown in blue, and constructs are expressing in green (panels a, $d$ and $g$ show H2Ax and TOPRO3; panels b, e and h show construct and TOPRO3; and panels c, $f$ and i show all three markers). Note how phosphohistone H2Ax protein can only be seen in nuclear puncta where WIds is being expressed. Note that not all cells have transfected with construct, and non-WIds expressing cells identifiable by their TOPRO3 labeled nuclei do not have corresponding $\mathrm{H} 2 \mathrm{Ax}$ puncta. $\mathrm{H} 2 \mathrm{Ax}$ puncta were found in all WIds-expressing cells, regardless of the nuclear distribution of WIds (panels a to $c$ show WIds in nuclear inclusions; panels $d$ to $f$ show WIds expressed in a strong diffuse manner throughout the nucleus). Scale bar $10 \mu \mathrm{m}$.

Finally, in order to confirm that Wlds altered nuclear localization, as well as expression, of cell stress proteins (as for cell cycle proteins shown in Figures 3 and 5), we investigated the expression and distribution of stress-induced phosphopro- tein 1 (STI1) in Wlds-transfected HEK293 cells (Figure 13). We chose to use STI1 as a marker of cell stress in vitro in order to expand our coverage of cell stress modifications beyond those genes/proteins incorporated on the array chip and also 

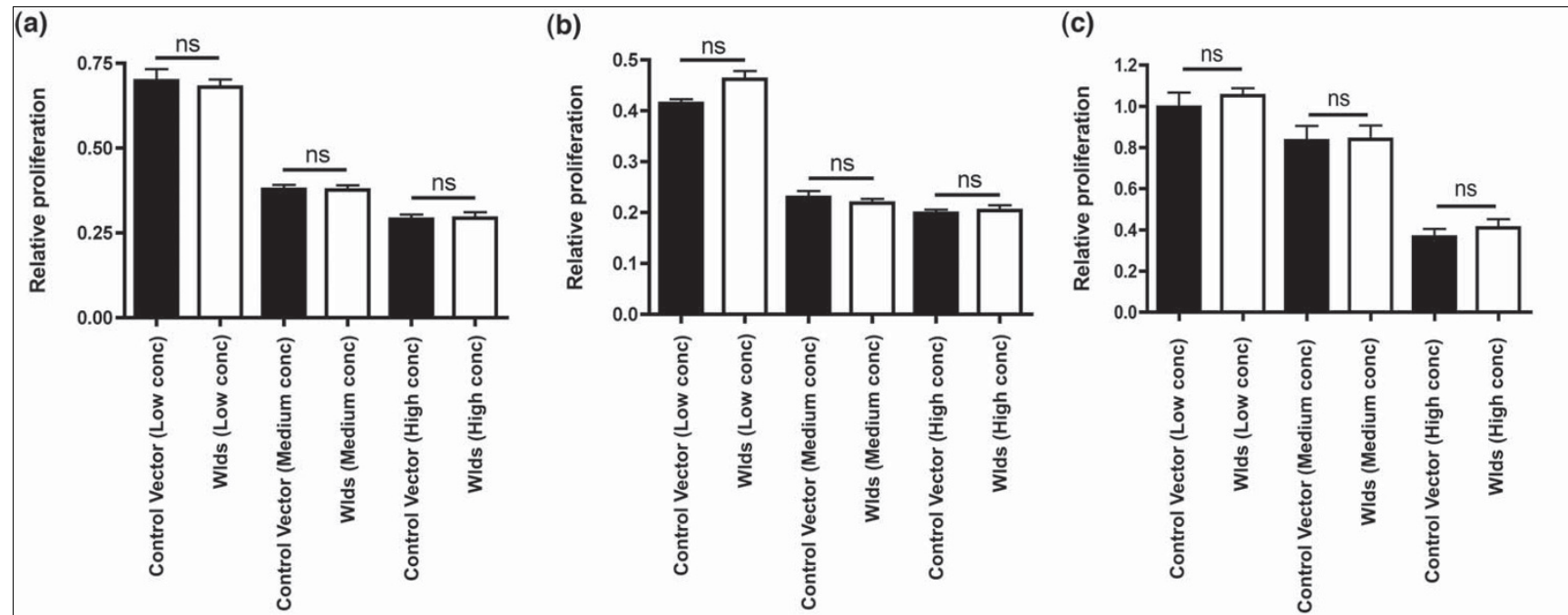

\section{Figure 6}

WIds does not influence late stages of cell cycle regulating cell proliferation in NT2 cells. Bar charts showing relative proliferation rates of NT2 cells transfected with either a control vector (black bars) or a WIds vector (white bars) at low, medium, and high concentrations. (a) Panel a shows no difference in proliferation at 48 hours after transfection using an MTT (3-[4,5-dimethylthiazolyl-2]-2,5-diphenyltetrazolium bromide) assay. (b) Panel b similarly shows no difference in proliferation at 72 hours after transfection using an MTT assay. (c) Panel c shows no difference in proliferation at 48 hours after transfection using a tritiated thymidine incorporation assay (all comparisons $P>0.05$; analysis fo variance with Tukey's post hoc test).

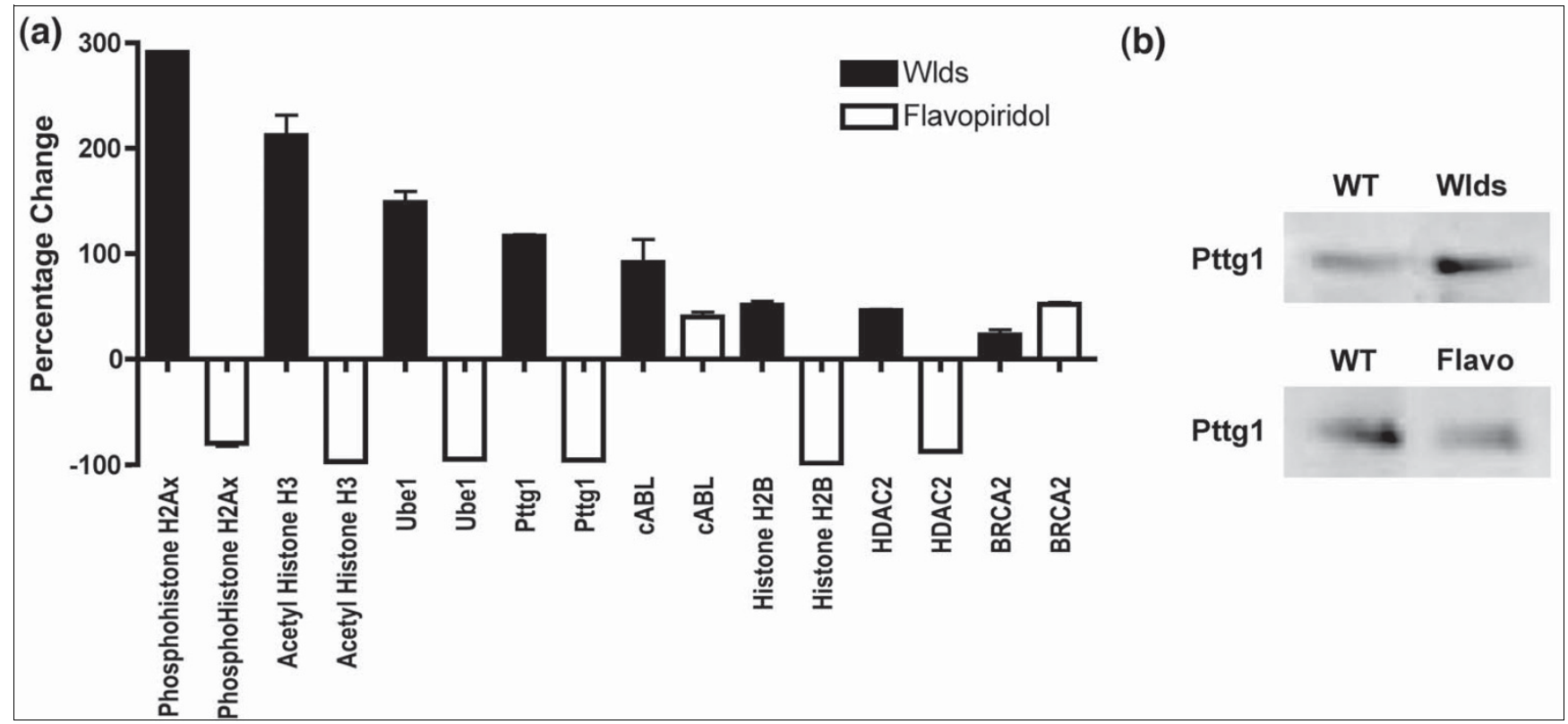

Figure 7

Pharmacological inhibition of cell cycle progression (flavopiridol) versus WIds: opposing changes in cell cycle proteins. (a) Bar chart showing protein expression assayed by quantitative fluorescent western blots in HEK293 cells transfected with WIds (black bars) or treated with exogenous flavopiridol (I0 $\mu \mathrm{mol} / /$; cell cycle inhibitor). Whereas W/ds induced increases in all cell cycle proteins, flavopiridol treatment led to decreased expression of the majority of proteins examined. (b) Representative Western blots showing pituitary tumor transforming gene I (Pttgl) protein levels in HEK293 cells comparing control versus WIds transfected cells (top panel) and control versus flavopiridol treated cells (bottom panel). Note how Pttgl protein levels are increased by WIds expression and decreased by flavopiridol treatment. 


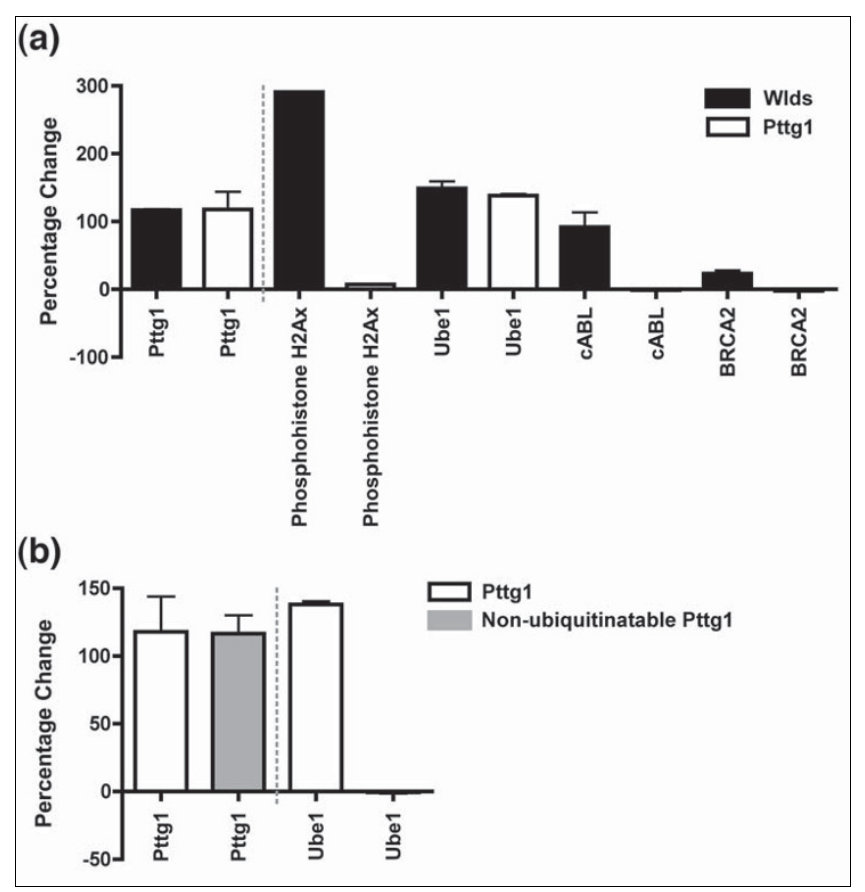

Figure 8

Over-expression of ubiquitinatable Pttgl is required to elicit changes in the cell cycle protein Ubel. Presented are quantitative fluorescent Western blots of HEK293 cells ( $n=3$ for all proteins). (a) Changes in four cell cycle proteins known to be modified by WIds after transfection with either a WIds construct (black bars) or a pituitary tumor transforming gene I (Pttg I) over-expression construct (white bars). The first portion of the graph shows normalized Pttg I levels accounting for differences in transfection efficiency. Note how Pttgl induced the same level of increase in ubiquitin-activating enzyme EI (Ubel) expression as Wlds but had no effect on the three other proteins. (b) changes in Ubel can only be induced by a ubiquitinatable form of Pttg I, because transfection with a non-ubiquitinatable form of Pttgl (gray bars) could not elicit any changes in Ubel expression (right portion of graph).

because STI1 protein levels are known to be modified in $W l d^{s}$ synapses in vivo [31]. Anti-STI1 antibodies revealed nuclear spots of STI1 in most cells expressing Wlds (Figure 13a-f). However, neighbouring cells not expressing $W l^{s}$ (because of less than $100 \%$ transfection efficiency) did not show any STI1 nuclear puncta. No STI1 staining was seen in control cells transfected with eGFP, indicating that stress responses were not simply occurring due to the presence of a large amount of foreign protein in the nucleus (Figure 13g-i). These findings were supported by data from quantitative Western blotting of STI1 protein levels in whole $W l d^{s}$ cerebellum in vivo, where STI1 levels were increased by $71.6 \pm 6.8 \%$ (mean \pm standard error of the mean; data not shown). Interestingly, we previously showed that STI1 protein levels are decreased in synapses protected by the $W l d^{s}$ gene in vivo [31]. The finding that nuclear STI1 immunoreactivity increases in $W l d^{s}$ transfected HEK293 cells suggests that some stress proteins may exhibit differential compartmental expression via redistribution within $W l d^{s}$-expressing neurons, rather than simply having altered expression levels.

\section{Discussion}

Here, we show that a strong correlation exists between modified cell cycle pathways and altered vulnerability of axonal and synaptic compartments in postmitotic, terminally differentiated neurons. We have demonstrated that the neuroprotective $W l d^{s}$ chimeric gene leads to a robust increase in expression of a broad spectrum of cell cycle-related genes in terminally differentiated neurons. These changes are indicative of an attempt to re-enter cell cycle in postmitotic neurons. Cell cycle alterations were identified in cerebellar neurons in vivo and could be replicated in HEK293 cell lines in vitro. We demonstrate that NAD, Pttg1/Ube1, and VCP pathways are all likely to be responsible for mediating distinct subsets of these downstream changes. Data from proliferation assays showing that $W l d^{s}$ does not alter cell division or proliferation rates suggests that terminally differentiated neurons expressing $W l d^{s}$ are pushed toward cell cycle reentry, but do not go on to enter proliferation and growth phases. We also show that expression of the $W l d^{s}$ gene leads to modifications in endogenous cell stress pathways that are likely to result from modifications in cell cycle status.

Contrary to previous suggestions that $W l d^{s}$-expressing neurons are 'normal', with the exception of a phenotype solely affecting axonal degeneration pathways [1], our experiments have revealed a novel cellular phenotype in $W l d^{s}$-expressing cells: modifications in cell cycle status. This finding brings together diverse observations from several disparate studies investigating $W l d^{s}$ mechanisms (changes in Pttg1/Ube1, $\mathrm{NAD}$, and VCP/p97 pathways), suggesting that modified cell cycle status might be a common endogenous pathway through which genomic and proteomic modifications downstream of $W l d^{s}$ can influence neuronal vulnerability.

\section{Pttg I/Ubel pathways}

Several studies have shown, using a range of experimental approaches and platforms, that $W l d^{s}$ robustly downregulates expression of Pttg1 mRNA [22,30]. Pttg1 plays a well established role in sister chromatid separation during mitosis, but recent data have identified an important additional role as a regulator of $\mathrm{G}_{1}$ to $\mathrm{S}$ phase cell cycle transition [32]. In the present study we showed that Pttg1 protein levels are significantly increased in $W l d^{s}$-expressing cells. The most parsimonious explanation for the differences between protein and mRNA levels is that decreases in mRNA are generated by a compensatory, self-regulating feedback loop responding to elevated levels of Pttg1 protein. Because Pttg1 is the only known substrate for the Ube $4 \mathrm{~b}$ component of the $W l d^{s}$ gene [56], it is tempting to speculate that elevated Pttg1 protein levels result from abnormal ubiquitination and targeting for degradation, caused by $W l d^{s}$-mediated alterations in the ubiquitin-proteasome pathway [28,29]. This finding also has implications for previous attempts to directly link Pttg1 to neuroprotection, because earlier studies examined neurodegenerative responses in Pttg1 null mice [22]. The current data suggest that repeating these experiments in Pttg1 over- 


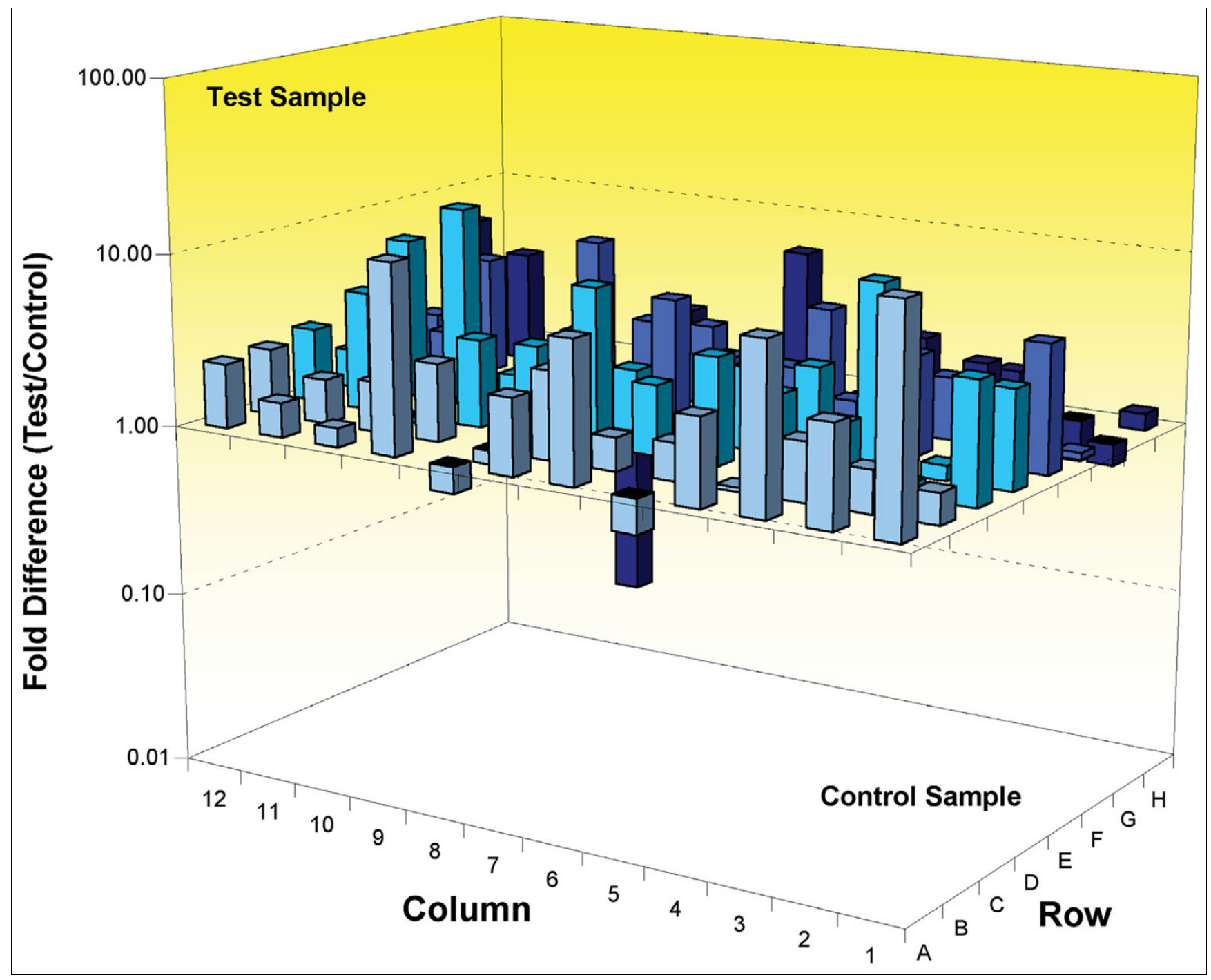

Figure 9

Upregulation of cell cycle genes in HEK293 cells treated with I mmol/l exogenous NAD. Three-dimensional bar chart taken from SuperArray analysis software (cell cycle SuperArray; see Materials and methods) showing fold difference in expression levels for 84 cell cycle related genes comparing vehicle treated HEK293 cells (control sample) with nicotinamide adenine dinucleotide (NAD) treated HEK293 cells (test sample). Individual genes with a greater than twofold expression change can be found in Table 2. NAD, nicotinamide adenine dinucleotide.

expressing mice might reveal a neuroprotective phenotype, although the undoubted contribution made by other pathways (see below) suggests that Pttg1 over-expression alone would be unlikely to confer the full levels of $W l d^{s}$-mediated neuroprotection.

We have also shown that increased Pttg1 protein levels induced by $W l d^{s}$ are responsible for mediating corresponding increases in expression of another cell cycle-related protein, namely Ube1. Thus, Pttg1 is likely to be a partial mediator of other cell cycle changes induced by $W l d^{s}$. We previously identified increased protein levels of Ube1 in a population of striatal synapses from $W l d^{s}$ mice known to be protected from degeneration [31], suggesting that Ube1 may also play a role in directly modulating degenerative pathways in synaptic compartments of neurons. Importantly, we also found that the ability of Pttg1 to increase Ube1 protein levels was abolished if Pttg1 was expressed in a non-ubiquitinatable form. Because Pttg1 is the only known substrate for the Ube $4 b$ component of the Wlds gene [56], these data suggest that modified ubiquitination of Pttg 1 by Ube $4 b$ (either in its native form or as part of the Wlds protein) is likely to be required to mediate downstream changes in proteins such as Ube1. However, at this stage we cannot rule out the possibility that other proteins in the ubiquitin pathway alongside Ube4b are also responsible for mediating this response.

\section{NAD pathways}

The most convincing evidence to date for the involvement of a single pathway in downstream mediation of the $W l d^{s}$ phe- 


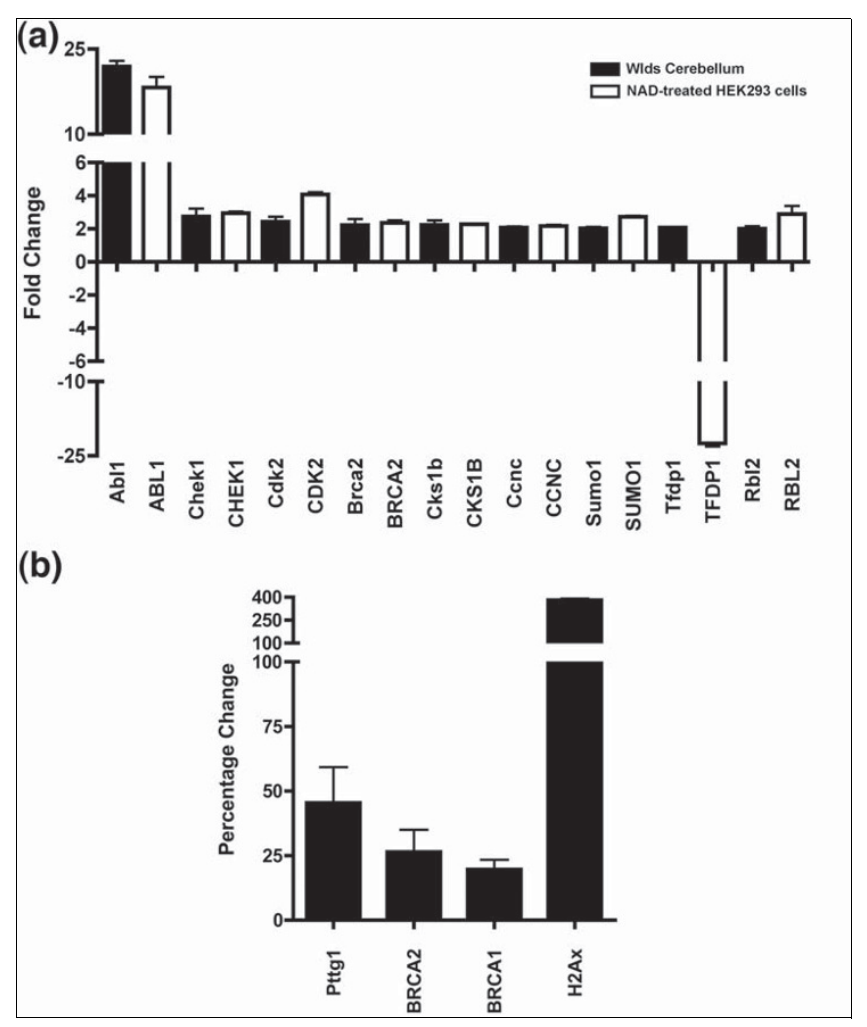

Figure 10

NAD-induced changes in cell cycle genes mimic WIds-induced changes. (a) Bar chart showing greater than twofold changes in cell cycle genes from SuperArray experiments on WIds cerebellum (black bars; see Table I) compared with nicotinamide adenine dinucleotide (NAD) treated HEK293 cells (white bars; see Table 2). Of the nine genes examined, eight responded similarly in both experimental groups. (b) Bar chart showing percentage difference in protein expression in NSC34 cells treated with I $\mathrm{mmol} / \mathrm{l}$ exogenous NAD as compared with control-treated cells.

notype has come from studies showing that the Nmnat1 portion of the chimeric $W l d^{s}$ gene confers a neuroprotective phenotype via modulation of NAD levels [23-25]. Here, we have shown that experimental manipulation of NAD levels mimics many (but by no means all) of the cell cycle changes induced by $W l d^{s}$. This finding raises the possibility that at least part of the NAD-mediated neuroprotective phenotype is generated by modulating cell cycle status. This suggestion is supported by several studies demonstrating that sirtuindependent pathways (which mediate the NAD neuroprotective phenotype [23]) play important roles in regulating cell cycle [38-40]. However, as with the Pttg1 findings discussed above, it is unlikely that NAD-mediated changes alone are sufficient to induce the full range of $W l d^{s}$-mediated cell cycle changes, because NAD over-expression alone is not thought to be sufficient to confer the full neuroprotective phenotype in vivo or in vitro [26,27].

\section{VCP/p97 pathways}

Alongside Pttg1 and NAD, pathways mediated by VCP (also known as p97 and CDC48) have also been shown to influence cell cycle [61]. For example, although VCP is predominantly a cytoplasmic protein, it is known to enter the nucleus during late $\mathrm{G}_{1}$ phase [37]. Here, we have shown that VCP, which is currently the only known binding partner for the Ube $4 \mathrm{~b}$ portion of $W l d^{s}[28,62]$, is localized to the nucleus in the majority of Wlds-expressing neurons. This is further corroborating evidence that cell cycle has been reactivated in terminally differentiated $W l d^{s}$ neurons and that they are progressing toward (or beyond) S phase. Although binding to VCP has not yet been demonstrated to be required for the $W l d^{s}$ phenotype, the present study suggests that if this is an important event, VCP may be acting via regulation of the cell cycle in a similar manner to Pttg1. Cell cycle events potentially attributable to VCP pathways detected in the current experiments include changes in expression levels of BRCA proteins that are known to interact with VCP in the nucleus [63].

\section{Cell cycle pathways and neurodegeneration}

The hypothesis that Wlds may be modifying neurodegenerative pathways in axons and synapses via modulation of the cell cycle is in keeping with other literature on somatic neurodegeneration, in which cell cycle is known to influence vulnerability significantly. For example, it is now known that postmitotic, terminally differentiated neurons in the adult nervous system are not 'permanently postmitotic', but rather depend upon the constant suppression of cell cycle pathways to maintain their arrested status [41]. The ability to control cell cycle pathways is therefore a critical factor in stopping neurons entering a vulnerable state, where the risk for neurodegenerative mechanisms being instigated increases significantly [41-44]. Numerous examples of cell cycle regulation gone awry, modifying neuronal vulnerability, can be found in neurodegenerative conditions such as motor neuron disease, Alzheimer's disease, and stroke [45,46]. Furthermore, pharmacologic manipulation of cell cycle progression has been used to confer somatic neuroprotection in animal models of traumatic brain injury and stroke $[47,48]$. The current data suggest that the influence of cell cycle status on neuronal vulnerability is likely to extend beyond neurodegenerative mechanisms resident in cell soma to incorporate independent degenerative pathways in axonal and synaptic compartments. The $W l d^{s}$ gene may therefore provide an important experimental tool for future investigations into pathways through which cell cycle status modulates neuronal vulnerability.

The current data are also likely to be important for interpreting previous and future studies concerning $W l d^{s}$-mediated neuroprotection both in vivo and in vitro. Because endogenous cell cycle and cell stress pathways are robustly modified by Wlds expression, it is difficult to imagine that $W l d^{s}$-expressing cells do not have any other covert cellular phenotypes alongside neuroprotection. These may introduce additional variables that could conceivably alter experimental outcomes (for example, comparing Nmnat over-expressing 
Table 2

\begin{tabular}{|c|c|c|c|c|c|c|}
\hline Gene name & Symbol & Acc. Number & Array cell & Fold change & SD & Cell cycle function \\
\hline $\begin{array}{l}\text { V-abl Abelson murine leukemia viral } \\
\text { oncogene homolog I }\end{array}$ & $A B L I$ & NM 005157 & $\mathrm{AOI}$ & 18.25 & 3.19 & $\begin{array}{l}\mathrm{S} \text { phase and DNA replication and } \\
\text { regulation }\end{array}$ \\
\hline Cullin 2 & CUL2 & NM 003591 & DIO & 14.32 & 1.89 & $\begin{array}{l}\mathrm{G}_{1} \text { phase and } \mathrm{G}_{1} / \mathrm{S} \text { transition and } \\
\text { checkpoint and arrest }\end{array}$ \\
\hline B-cell CLL/lymphoma 2 & $B C L 2$ & NM 000633 & A09 & 12.44 & 2.12 & Regulation \\
\hline $\begin{array}{l}\text { Cyclin-dependent kinase inhibitor } 2 B \\
\text { (pI5, inhibits CDK4) }\end{array}$ & $C D K N 2 B$ & NM 004936 & D03 & 11.03 & 2.37 & $\begin{array}{l}\text { Checkpoint and arrest and negative } \\
\text { regulator }\end{array}$ \\
\hline Anaphase promoting complex subunit 4 & ANAPC4 & NM 013367 & $\mathrm{~A} 03$ & 9.17 & 0.27 & $\begin{array}{l}G_{2} \text { phase and } G_{2} / M \text { transition and } \\
\text { regulation }\end{array}$ \\
\hline Cullin 3 & CUL3 & NM 003590 & DII & 8.46 & 0.65 & $\begin{array}{l}\mathrm{G}_{1} \text { phase and } \mathrm{G}_{1} / \mathrm{S} \text { transition and } \\
\text { checkpoint and arrest }\end{array}$ \\
\hline $\begin{array}{l}\text { Cyclin-dependent kinase } 5 \text {, regulatory } \\
\text { subunit I (p35) }\end{array}$ & CDK5RI & NM 003885 & $\mathrm{C} 07$ & 8.00 & 1.66 & Regulation \\
\hline RADI homolog & RADI & NM 002853 & F09 & 7.43 & 0.48 & Checkpoint and arrest \\
\hline SERTA domain containing I & SERTADI & NM 013376 & G06 & 7.41 & 0.27 & $\mathrm{G}_{2}$ phase and $\mathrm{G}_{2} / \mathrm{M}$ transition \\
\hline Ataxia telangiectasia and $\operatorname{Rad} 3$ related & ATR & NM 001184 & $\mathrm{~A} 06$ & 6.51 & 0.36 & Checkpoint and arrest \\
\hline Ubiquitin-activating enzyme EI & UBEI & NM 003334 & $\mathrm{G} 12$ & 6.48 & 1.19 & S phase and DNA replication \\
\hline Dynamin 2 & DNM2 & NM 004945 & EOI & 5.38 & 0.37 & $\mathrm{G}_{2}$ phase and $\mathrm{G}_{2} / \mathrm{M}$ transition \\
\hline Cell division cycle 16 homolog & $\mathrm{CDCl} 6$ & NM 003903 & $\mathrm{COI}$ & 4.94 & 0.43 & M phase \\
\hline HUSI checkpoint homolog & HUSI & NM 004507 & E07 & 4.89 & 0.74 & Checkpoint and arrest \\
\hline Cyclin-dependent kinase 8 & CDK8 & NM 001260 & $\mathrm{Cll}$ & 4.86 & 1.25 & Regulation \\
\hline RAD5I homolog (RecA homolog) & RAD5 I & NM 002875 & $\mathrm{FII}$ & 4.77 & 3.09 & M phase \\
\hline $\begin{array}{l}\text { Menage a trois homolog } \mathrm{I} \text {, cyclin } \mathrm{H} \\
\text { assembly factor }\end{array}$ & MNATI & NM 002431 & F05 & 4.51 & 0.18 & $G_{2}$ phase and $G_{2} / M$ transition \\
\hline $\begin{array}{l}\text { Tumor protein p53 (Li-Fraumeni } \\
\text { syndrome) }\end{array}$ & TP53 & NM 000546 & GII & 4.40 & 1.48 & Checkpoint and arrest \\
\hline Cyclin-dependent kinase 2 & $C D K 2$ & NM 001798 & $\mathrm{C} 05$ & 4.07 & 0.24 & Checkpoint and arrest and regulation \\
\hline Anaphase promoting complex subunit 2 & ANAPC2 & NM 013366 & $\mathrm{~A} 02$ & 3.76 & 0.63 & $\mathrm{G}_{1}$ phase and $\mathrm{G}_{\mathrm{I}} / \mathrm{S}$ transition and regulation \\
\hline $\begin{array}{l}\text { Growth arrest and DNA-damage- } \\
\text { inducible, alpha }\end{array}$ & GADD 45A & NM 001924 & E03 & 3.70 & 0.08 & Checkpoint and arrest and regulation \\
\hline $\begin{array}{l}\text { Cyclin-dependent kinase inhibitor IB } \\
\text { (p27, KipI) }\end{array}$ & CDKNIB & NM 004064 & DOI & 3.65 & 0.25 & $\begin{array}{l}\mathrm{G}_{1} \text { phase and } \mathrm{G}_{1} / \mathrm{S} \text { transition and } \\
\text { checkpoint and arrest }\end{array}$ \\
\hline Cyclin-dependent kinase inhibitor 3 & CDKN3 & NM 005192 & D04 & 3.36 & 0.09 & $\begin{array}{l}\mathrm{G}_{1}+\mathrm{G}_{2} \text { phase and } \mathrm{G}_{1} / \mathrm{S}+\mathrm{G}_{2} / \mathrm{M} \text { transition } \\
\text { and checkpoint and arrest }\end{array}$ \\
\hline $\begin{array}{l}\text { CDK5 regulatory subunit associated } \\
\text { protein I }\end{array}$ & CDK5RAPI & NM 016408 & $\mathrm{C} 08$ & 3.32 & 0.06 & $G_{2}$ phase and $G_{2} / M$ transition \\
\hline Cyclin F & CCNF & NM 001761 & B07 & 3.22 & 0.20 & M phase and regulation \\
\hline Cyclin-dependent kinase 6 & CDK6 & NM 001259 & $\mathrm{C} 09$ & 3.22 & 0.23 & $\mathrm{G}_{1}$ phase and $\mathrm{G}_{\mathrm{I}} / \mathrm{S}$ transition and regulation \\
\hline DIRAS family, GTP-binding RAS-like 3 & DIRAS3 & NM 004675 & $\mathrm{~A} 04$ & 3.15 & 0.12 & $?$ \\
\hline CHKI checkpoint homolog & CHEKI & NM_00I274 & D05 & 2.95 & 0.15 & Checkpoint and arrest \\
\hline Nibrin & NBN & NM 002485 & F07 & 2.89 & 0.03 & Checkpoint and arrest \\
\hline Retinoblastoma-like $2(p \mid 30)$ & RBL2 & NM 005611 & G04 & 2.89 & 0.83 & Negative regulator \\
\hline Cell division cycle 34 homolog & CDC34 & NM 004359 & $\mathrm{CO4}$ & 2.86 & 0.14 & $\begin{array}{l}G_{1} \text { phase and } G_{1} / S \text { transition and } \\
\text { checkpoint and arrest }\end{array}$ \\
\hline Cyclin G2 & CCNG2 & NM 004354 & B09 & 2.81 & 0.18 & Checkpoint and arrest \\
\hline $\mathrm{BCL2}$-associated $\mathrm{X}$ protein & $B A X$ & NM 004324 & $\mathrm{~A} 07$ & 2.76 & 0.06 & Negative regulator \\
\hline Proliferating cell nuclear antigen & PCNA & NM 182649 & F08 & 2.76 & 0.19 & S phase and DNA replication \\
\hline $\begin{array}{l}\text { SMT3 suppressor of mif two } 3 \text { homolog } \\
\text { I }\end{array}$ & SUMOI & NM 003352 & G08 & 2.73 & 0.10 & S phase and DNA replication \\
\hline $\begin{array}{l}\text { Cyclin-dependent kinase inhibitor IA } \\
\text { (p2I, CipI) }\end{array}$ & CDKNIA & NM 000389 & $\mathrm{Cl} 2$ & 2.67 & 0.08 & Checkpoint and arrest and regulation \\
\hline
\end{tabular}


Table 2 (Continued)

\begin{tabular}{|c|c|c|c|c|c|c|}
\hline Hect domain and RLD 5 & HERC5 & NM 016323 & E06 & 2.54 & 0.04 & $\mathrm{G}_{2}$ phase and $\mathrm{G}_{2} / \mathrm{M}$ transition \\
\hline Cyclin-dependent kinase 4 & CDK4 & NM 000075 & $\mathrm{C} 06$ & 2.52 & 0.13 & $\mathrm{G}_{1}$ phase and $\mathrm{G}_{1} / \mathrm{S}$ transition and regulation \\
\hline G-2 and S-phase expressed I & GTSEI & NM 016426 & E05 & 2.49 & 0.10 & $\mathrm{G}_{2}$ phase and $\mathrm{G}_{2} / \mathrm{M}$ transition \\
\hline Cyclin T2 & CCNT2 & NM 001241 & $\mathrm{~B} 12$ & 2.41 & 0.16 & $\begin{array}{l}\mathrm{G}_{2} \text { phase and } \mathrm{G}_{2} / \mathrm{M} \text { transition and } \\
\text { regulation }\end{array}$ \\
\hline Breast cancer 2 , early onset & $B R C A 2$ & NM 000059 & $\mathrm{~A} / 2$ & 2.36 & 0.27 & Checkpoint and arrest and regulation \\
\hline Retinoblastoma-like I (p|07) & $R B L I$ & NM 002895 & G03 & 2.31 & 0.04 & Negative regulator \\
\hline $\begin{array}{l}\text { MCM5 minichromosome maintenance } \\
\text { deficient } 5\end{array}$ & MCM5 & NM 006739 & F03 & 2.28 & 0.13 & S phase and DNA replication \\
\hline $\begin{array}{l}\text { CDC28 protein kinase regulatory } \\
\text { subunit IB }\end{array}$ & CKSIB & NM 001826 & D07 & 2.28 & 0.03 & $\begin{array}{l}\mathrm{G}_{2} \text { phase and } \mathrm{G}_{2} / \mathrm{M} \text { transition and } \\
\text { regulation }\end{array}$ \\
\hline Cell division cycle 20 homolog & CDC20 & NM 001255 & $\mathrm{CO3}$ & 2.24 & 0.17 & Regulation \\
\hline Cyclin C & CCNC & NM 005190 & B03 & 2.16 & 0.14 & Regulation \\
\hline MAD2 mitotic arrest deficient-like 2 & MAD2L2 & NM 006341 & EII & 2.03 & 0.46 & Checkpoint and arrest \\
\hline Transcription factor Dp-I & TFDPI & NM_007III & G09 & -22.50 & 1.04 & Regulation \\
\hline
\end{tabular}

NAD, nicotinamide adenine dinucleotide; SD, standard deviation.
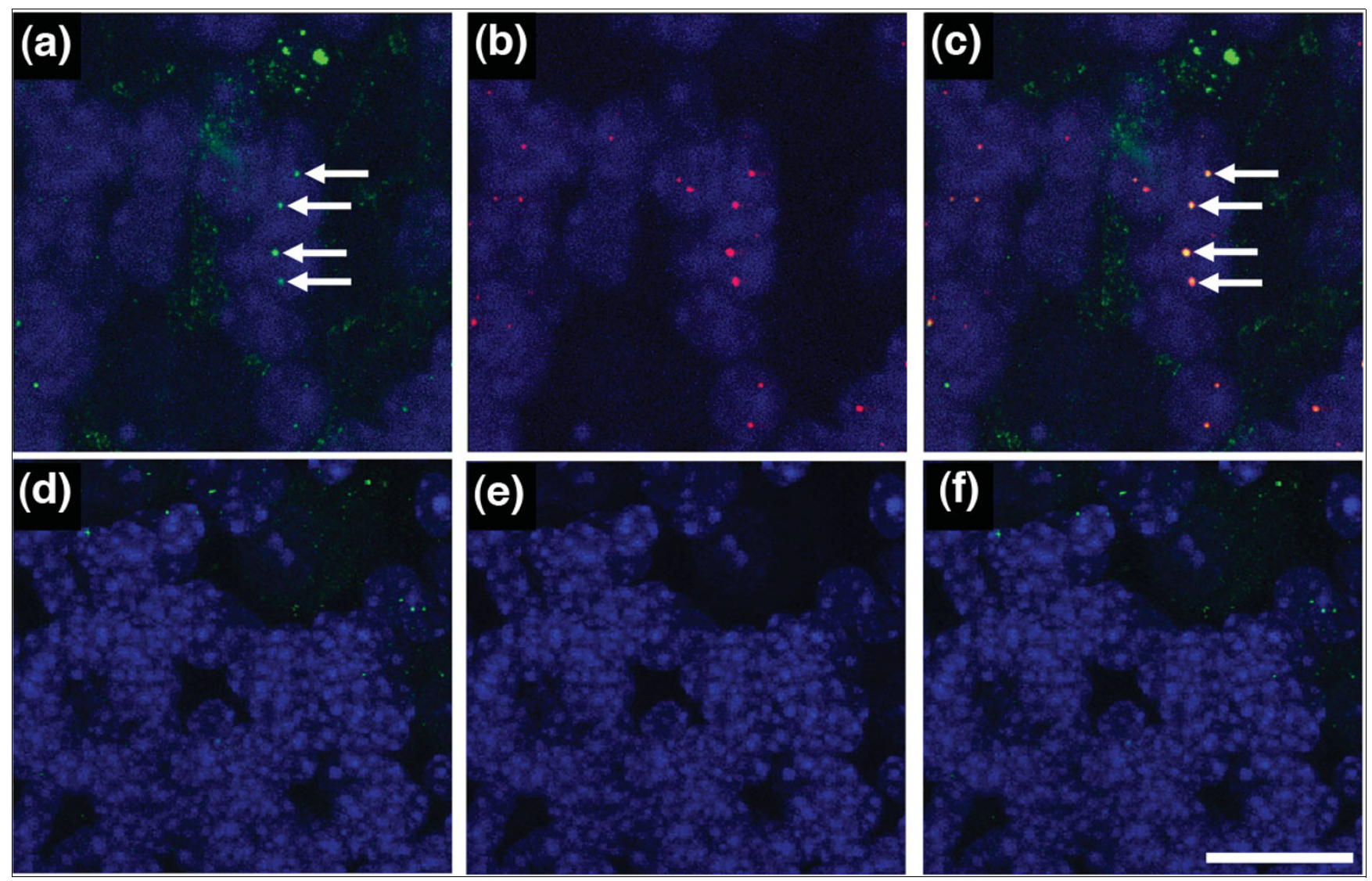

\section{Figure II}

Increased nuclear expression of cell cycle marker VCP corresponding with WIds expression in mouse cerebellum. Confocal micrographs of cerebellar granule cells from (a-c) WIds and (d-f) wild-type mice. Valosin-containing protein (VCP) is shown in green, the nuclear marker TOPRO3 is shown in blue, and WIds protein in red (panels a and $d$ show VCP and TOPRO3; panels $b$ and e show WIds and TOPRO3; and panels $\mathrm{c}$ and $\mathrm{f}$ show all three markers).

Note how VCP protein can be seen in nuclear puncta with high frequency where WIds is being expressed (arrows in panels a and $c$ show four out of nine examples in this field of view). The majority of WIds puncta coincided with VCP puncta. Nuclear puncta of VCP were rarely observed in wild-type cerebellar granule cells. As expected, VCP was detectable as diffuse staining in the cytoplasm of neurons in both strains of mice. Scale bar $=20 \mu \mathrm{m}$. 


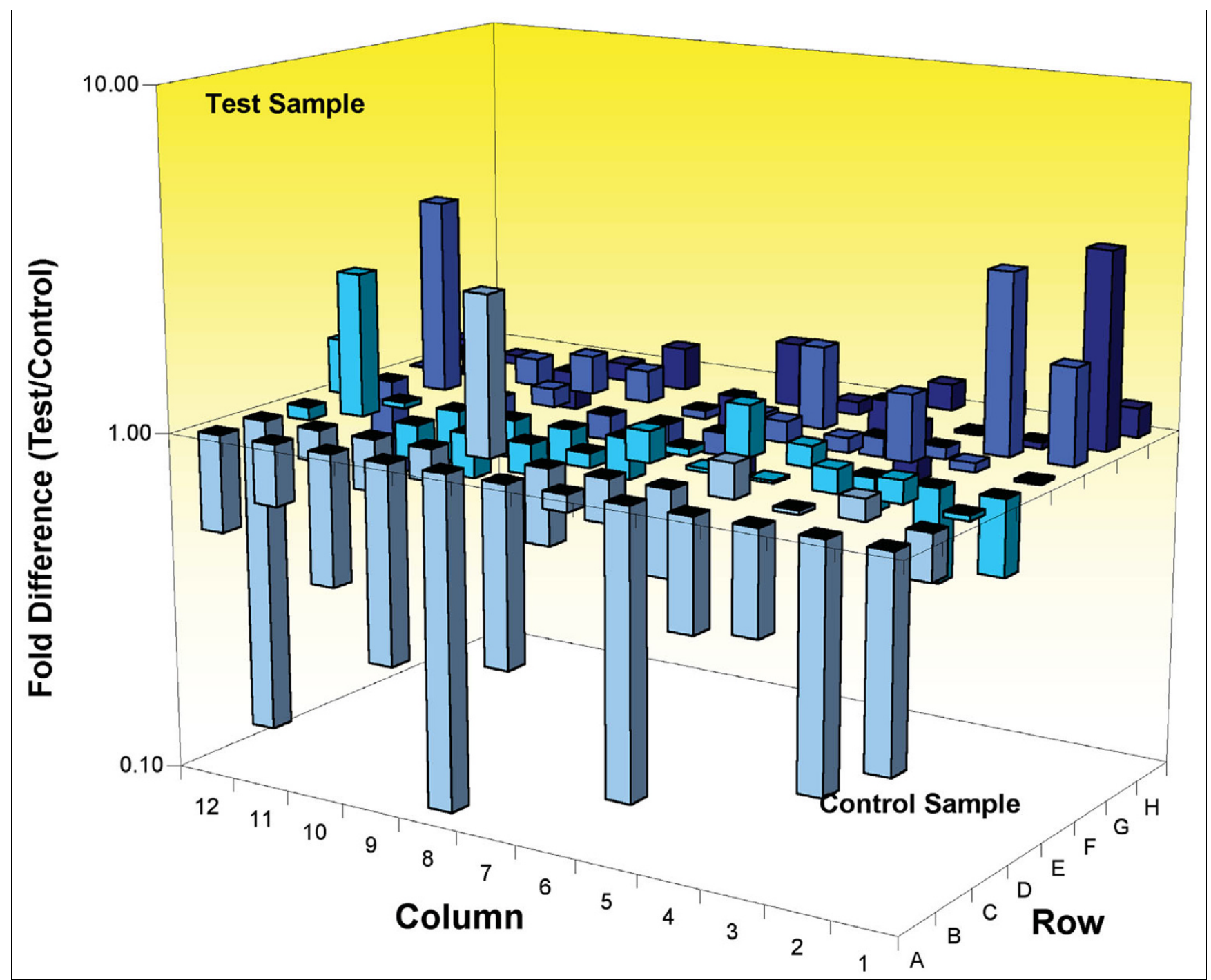

\section{Figure 12}

Widespread alterations in cell stress genes in uninjured/untreated WIds mouse cerebellum in vivo. Three-dimensional bar chart taken from SuperArray analysis software (cell stress SuperArray; see Materials and methods) showing fold difference in expression levels for 84 cell stress related genes comparing wild-type cerebellum (control sample) with WIds cerebellum (test sample). Individual genes with a greater than twofold expression change can be found in Table 3.

cells in vivo with cells exposed to exogenous NAD in vitro [23-27]).

Current opinion suggests that cell cycle re-entry is damaging to neurons, whereas blocking cell cycle decreases vulnerability [41-44]. The finding that the neuroprotective $W l d^{s}$ gene pushes neurons toward cell cycle re-entry therefore appears at odds with this hypothesis. There are two possible explanations for this discrepancy. First, it is possible that the basic principle of re-entry is bad/suppression is good may not hold for all neurodegenerative pathways. Second, and perhaps more plausibly, it is possible that $W l d^{s}$ acts to 'prime' the cell against future neurodegenerative insults by inducing early-stage cell cycle changes - and cell stress modifications without going as far as affecting proliferation and growth stages. This potential mechanism of action is in keeping with a known role for preconditioning, sublethal 'priming' events in conferring neuroprotection by modifying endogenous stress pathways [64-67].

\section{Cell stress pathways and WIds}

Our finding that cell stress pathways are also modified in $W l d^{s}$ mice, suggesting a possible 'primed state' of $W l d^{s}$ neurons, is in keeping with the findings of other recent studies. For example, it was recently demonstrated that the NMNAT1 component of the chimeric $W l d^{s}$ gene has functions alongside those involving $\mathrm{NAD}$, acting as a chaperone for stressresponse proteins such as heat shock protein-70 [68] (Wishart TM, Gillingwater TH, unpublished observations). In addition, we have recently shown that the mitochondrial 
Table 3

\begin{tabular}{|c|c|c|c|c|c|c|}
\hline Gene name & Symbol & Acc. number & Array cell & Fold change & SD & Cell stress and toxicity function \\
\hline $\begin{array}{l}\text { Serine (or cysteine) peptidase inhibitor, clade E, } \\
\text { member I }\end{array}$ & Serpine I & NM 00887I & G0I & 3.73 & 0.29 & Inflammation \\
\hline Interleukin I beta & $I I l b$ & NM 008361 & EII & 3.69 & 0.82 & Inflammation \\
\hline Transformed mouse $3 T 3$ cell double minute 2 & Mdm2 & NM 010786 & F02 & 3.34 & 0.15 & Growth arrest and senescence \\
\hline Cytochrome P450, family 2, subfamily a, polypeptide 5 & Сур2a5 & NM 007812 & B08 & 2.92 & 0.48 & Oxidative or metabolic stress \\
\hline Fas ligand (TNF superfamily, member 6) & Fasl & NM 010177 & $\mathrm{CII}$ & 2.62 & 0.71 & Apoptosis signaling \\
\hline Bcl2-like I & $B c \mid 2 I I$ & NM 009743 & $\mathrm{~A} 04$ & -2.11 & 0.25 & Apoptosis signaling \\
\hline Cyclin C & Conc & NM 016746 & AlO & -2.44 & 0.46 & Proliferation and carcinogenesis \\
\hline Chemokine ( $\mathrm{C}-\mathrm{C}$ motif) ligand $2 \mathrm{Ib}$ & $C c 12 I b$ & NM 011124 & $\mathrm{~A} 07$ & -3.37 & 0.25 & Inflammation \\
\hline Chemokine ( $\mathrm{C}-\mathrm{C}$ motif) ligand 4 & Ccl4 & NM 013652 & A09 & -3.86 & 0.40 & Inflammation \\
\hline Annexin A5 & Anxa5 & NM 009673 & $\mathrm{AOI}$ & -4.00 & 1.50 & Apoptosis signaling \\
\hline Ataxia telangiectasia mutated homolog (human) & Atm & NM 007499 & $\mathrm{~A} 02$ & -4.99 & 0.70 & DNA damage and repair \\
\hline Caspase I & Caspl & NM 009807 & A05 & -6.81 & 7.58 & Apoptosis signaling \\
\hline $\begin{array}{l}\text { Cytochrome P450, family } 3 \text {, subfamily a, polypeptide } \\
\text { II }\end{array}$ & Сур3аІІ & NM 007818 & $\mathrm{~B} 12$ & -8.60 & 0.52 & Oxidative or metabolic stress \\
\hline Chemokine (C-C motif) ligand 3 & $\mathrm{Ccl} 3$ & NM 011337 & A08 & -9.50 & 2.39 & Inflammation \\
\hline
\end{tabular}

eGFP, enhanced green fluorescent protein; SD, standard deviation.

proteome is modified at a basal level in protected $W l d^{s}$ synapses [31], suggesting intrinsic differences in the ability to respond to cell stress stimuli. This hypothesis has received experimental support from another recent study showing that NMNAT1 can protect against mitochondrial and oxidative stress [69].

Our study has identified possible individual stress-related proteins that may play an important role in the cell stress response in $W l d^{s}$ neurons. Interestingly, several of these proteins have already been implicated in other neuroprotective situations. For example, STI1 - shown in previous work [31] and the present study to have altered levels and subcellular localization in $W l d^{s}$-expressing cells - appears to play an important role in neuroprotection and neuritogenesis [70] as well as in cell proliferation [71,72]. Further investigations into the in vivo role played by individual cell stress proteins modified by $W l d^{s}$, such as STI1, in modulating neuronal phenotypes may therefore provide important insights into mechanisms underlying axonal and synaptic vulnerability.

\section{Conclusion}

We have identified a strong and robust correlation between modified cell cycle pathways and altered vulnerability of axonal and synaptic compartments in terminally differentiated neurons by showing that the neuroprotective $W l d^{s}$ gene modifies cell cycle and cell stress status in vivo and in vitro. We conclude that $W l d^{s}$-expressing cells have a potentially important, previously unreported cellular phenotype that is characterized by reactivation of normally suppressed cell cycle pathways in terminally differentiated neurons. We pro- pose that multiple NAD-, Pttg1/Ube1-, and VCP-dependent pathways are likely to be required to modulate these cell cycle changes. The data suggest that further investigations into the role of cell cycle and cell stress status induced by Wlds are likely to provide insights into mechanisms that regulate axonal and synaptic degeneration in neurodegenerative disease.

\section{Materials and methods \\ Mouse tissue and cell lines/treatments}

Natural mutant $\mathrm{C}_{57} \mathrm{Bl6} / \mathrm{Wld}^{\mathrm{S}}\left(\right.$ Wld $\left.^{S}\right)$ mice and $\mathrm{C}_{57} \mathrm{Bl} / 6$ (wild type) mice (all aged 6 to 8 weeks) were obtained from Harlan Olac Laboratories (Bicester, UK) and housed within the animal care facilities in Edinburgh. Mice (minimum three mice per experimental group) were killed by cervical dislocation and the cerebellum was rapidly removed.

HEK293 and NSC34 (a mouse motor neuron-like cell line [73]) cells were maintained in Dulbecco's modified Eagle's medium with $10 \%$ fetal bovine serum and $1 \%$ penicillin/streptomycin (Invitrogen, Carlsbad, CA, USA) at $37^{\circ} \mathrm{C}$ in $5 \%$ carbon dioxide. For transfection with eGFP-Wlds [22], Pttg1 [55], and non-ubiquitinatable Pttg1 [57], 5 mg of the DNA was mixed with $10 \%$ (vol/vol) $\mathrm{CaCl}_{2}$. An equal volume of $\mathrm{N}, \mathrm{N}-$ bis(2-hydroxyethyl)-2-aminoethanesulfonic acid was added and the solution gently dropped onto the HEK293 cell culture [22]. For some experiments, $1 \mathrm{mmol} / \mathrm{l} \mathrm{NAD}$ (Sigma-Aldrich, Gillingham, UK) or $10 \mu \mathrm{mol} / \mathrm{l}$ Flavopiridol (obtained through the National Cancer Institute, Rockville, MD, USA) was added to the medium. All cells were incubated for 4 to 5 days and were checked on a phase contrast microscope before 

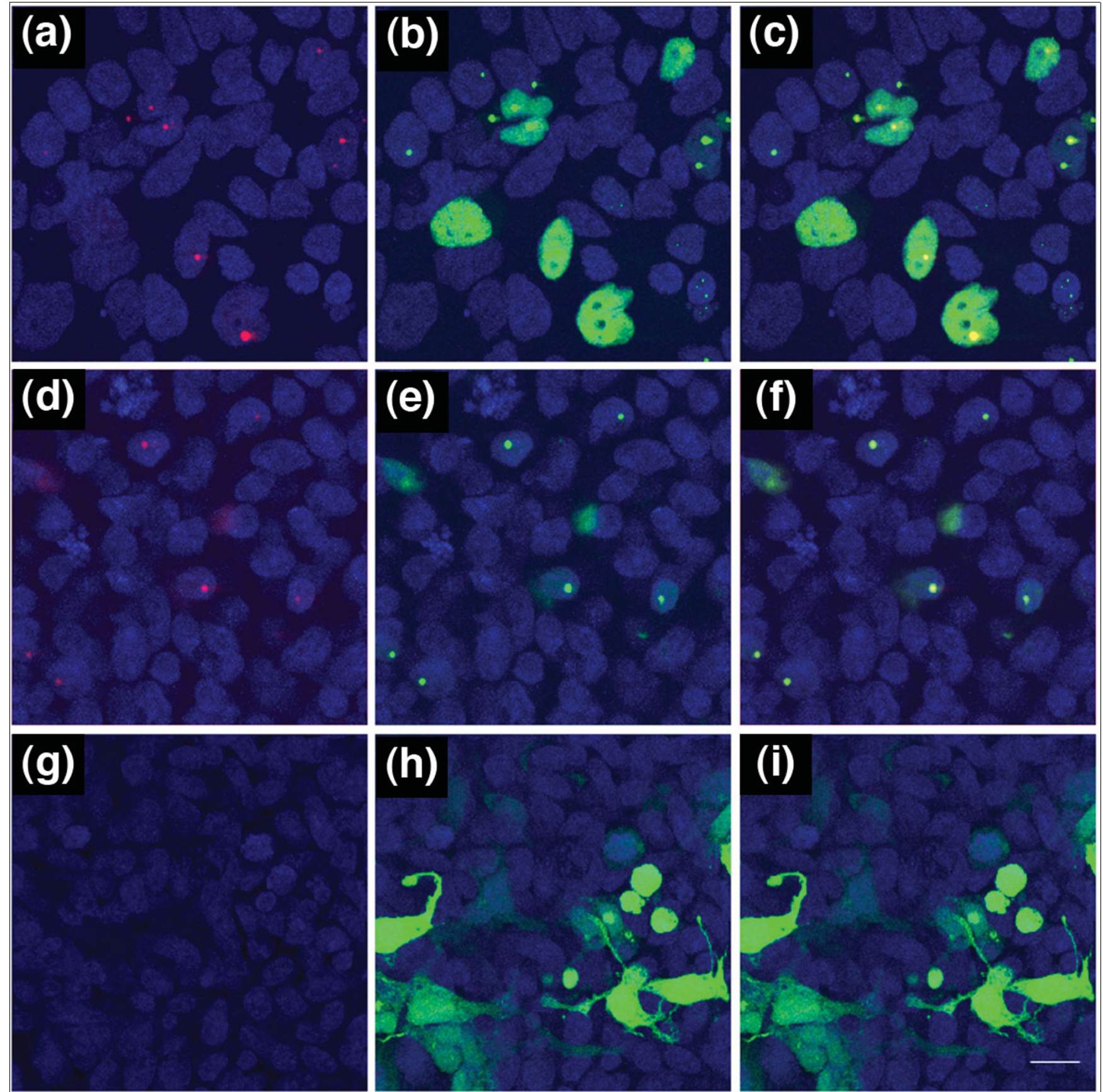

\section{Figure 13}

Increased nuclear expression of cell stress marker STII corresponding with WIds expression in HEK293 cells. Confocal micrographs of HEK293 cells transfected with either an (a-f) enhanced green fluorescent protein (eGFP)-Wlds construct or an (g-i) eGFP alone control construct. Stress induced phosphoprotein I (STII) is shown in red, the nuclear marker TOPRO3 is shown in blue, and WIds protein in green (panels a, $\mathrm{d}$ and $\mathrm{g}$ show STII and TOPRO3; panels b, e and $\mathrm{h}$ show construct and TOPRO3; and c, $\mathrm{f}$ and $\mathrm{i}$ show all three markers). Note how STII protein can be seen in nuclear puncta with high frequency where WIds is being expressed, but was never observed in non-WIds-expressing cells. The majority of WIds puncta coincided with STII puncta. Nuclear puncta of STII were never observed in eGFP transfected control cells (panels g-i). Scale bar $=10 \mu \mathrm{m}$.

proceeding to either immunocytochemistry/microscopy or extraction of protein and/or RNA (at least three cultures for all transfections and treatments).

\section{RNA and protein extraction}

RNA was extracted from cerebella of age-matched and sexmatched mice, or HEK293 cells, in tri-reagent (Sigma) in 
accordance with the manufacturer's instructions, as previously described [22]. Protein was extracted from cerebella of age-matched and sex-matched mice, or HEK293 cells, in RIPA buffer with $10 \%$ protease inhibitor cocktail (Sigma) [31].

\section{Super arrays}

Mouse cell cycle (PAMM-O2OA), cell stress (PAM-O03A), and human cell cycle (PAHS-O20A) focused pathway arrays (Tebubio Superarrays, Peterborough, UK) in 96-well plate format, compatible with an ABI 7000 real-time PCR machine, were used to assay gene expression changes (three comparisons for each array type). Samples were added to the reaction plates and signal amplification by PCR was carried out using a Sybr-Green '1 step qRT-PCR kit' (Invitrogen). Analysis was carried out using the Analysis Suite spreadsheet provided by Tebubio Superarrays. The absence of DNA contamination and efficiency of amplification was confirmed using the analysis software provided. Gene functions listed in Tables 1 to 3 were obtained from the SuperArray product specification sheets. Raw data for all of these array experiments can be found online [74].

\section{Quantitative Western blots}

Cerebellar/cultured cell protein was separated by SDS-PAGE on $4 \%$ to $20 \%$ pre-cast NuPage $4 \%$ to $12 \%$ Bis Tris gradient gels (Invitrogen) and then transferred to PVDF membrane overnight. The membranes were then blocked using Odyssey blocking buffer (Li-COR Biosciences, Lincoln, Nebraska, USA) and incubated with primary antibodies as per manufacturers instructions (BRCA2, cAbl, CCL3 and E1 ubiquitin activating enzyme [Abcam, Cambridge, MA, USA]; anti-HDAC2 clone $3 \mathrm{~F}_{3}$, anti-histone $\mathrm{H}_{2} \mathrm{~B}$ and anti acetyl histone $\mathrm{H}_{3}$ [Lake Placid Biologicals, Lake Placid, NY, USA]; Pds1 Ab1 clone DCS280/Anti-Pttg1 [LabVision Corporation, Freemont, CA, USA]; and antiphosphohistone H2Ax [Upstate, Billerica, MA, USA]). Anti-Wlds antibodies were a kind gift from Dr Michael Coleman and were used as previously described [20,21]. Odyssey secondary antibodies were added in accordance with the manufacturer's instructions (Goat anti rabbit IRDye 680 and Goat anti mouse IRDye 80o). Blots were imaged using an Odyssey Infrared Imaging System (Li-COR Biosciences). The scan resolution of the instrument ranges from 21 to $339 \mu \mathrm{m}$, and in this study blots were imaged at $169 \mu \mathrm{m}$. Quantification was performed on single channels with the analysis software provided. Bands were identified according to their relative molecular weight, as detailed in the manufacturer's antibody notes. Bands were delineated using Odyssey software and the arbitrary fluorescence intensity calculated by the software. For each membrane, scans were carried out at three different intensities in order to minimize possible user error in determining correct scan intensities or over-saturation of the membrane. The average of these three separate scans (giving an $n$ of 1 per membrane) was used for further analysis.

\section{NT2 cell proliferation assays}

MTT assays were carried out in 96-well plates. One hundred micrograms of MTT was added to 6,00o cells per well of NT2 cells transfected with control (vector only) or Wlds constructs (200 ng [low dose], $600 \mathrm{ng}$ [medium dose], and 1,200 ng [high dose]), and incubated for 3 hours. Media were then removed and formazan crystals dissolved in $50 \mu$ dimethyl sulfoxide. The absorbance of the dimethyl sulfoxide was read at $545 \mathrm{~nm}$ to estimate cell number. For $3 \mathrm{H}$-thymidine incorporation assays, $3 \times 10^{5} \mathrm{NT} 2$ cells per well of a 24-well plate were transfected with control (vector only) or Wlds constructs, as detailed above, and proliferation assayed at 48 hours. Mitogenesis was estimated from the measurement of nuclear $3 \mathrm{H}$-thymidine incorporation. Cells were incubated with $0.2 \mathrm{Ci} 3 \mathrm{H}$-thymidine (specific activity 70-95 Ci/mmol; Amersham Biosciences, Little Chalfont, UK) for the last 5 hours of culture incubation. Cells were then washed twice in ice-cold phosphate-buffered saline (PBS), followed by $1 \mathrm{ml}$ cold 5\% trichloroaceteic acid, and left on ice for 20 minutes. Then, $0.1 \mathrm{~mol} / \mathrm{l}$ sodium hydroxide was added to the cells before transfer to $4 \mathrm{ml}$ of scintillant. Radioactive counts were determined by scintillation counting. Experiments comprised four replicates each and were performed on at least two separate occasions.

\section{Immunocytochemistry}

Immunofluorescence staining was performed on either freshly cut $(20 \mu \mathrm{m}$ or $100 \mu \mathrm{m})$ cerebellar slices or HEK293 cells, fixed in $4 \%$ paraformaldehyde (Fisher Scientific, Loughborough, UK). Slices or cultured cells were incubated overnight in serum blocker consisting of $4 \%$ bovine serum albumin (Sigma) and 0.5\% Triton X-100 (Sigma) in PBS. In cerebellar slices, anti-Wlds antibodies (1:500 dilution in serum blocking solution [8]) were applied overnight and, after washing with PBS saline, a TRITC-conjugated anti-rabbit secondary antibody (DAKO, Glostrup, Denmark) was applied overnight. Primary antibodies, including Ube1 (Abcam), VCP (Abcam), Sti1 (BD Transduction Laboratories, San Jose, CA, USA), and phosphohistone H2Ax (Upstate), were also used at concentrations specified by the manufacturers. Anti-rabbit/mouse FITC-conjugated secondary antibodies (DAKO) were used on cerebellar slices and anti-rabbit/ mouse TRITC-conjugated secondary antibodies (DAKO) were used on HEK293 cells. Secondary antibody only controls were also carried out and confirmed the specificity of antibodies used (data not shown). Finally, cerebellar slices and cultured cells were then washed in PBS and incubated in TOPRO 3 (Molecular Probes, Carlsbad, CA, USA) for 10 minutes before mounting in Mowoil.

Staining was visualised on a laser scanning confocal microscope (BioRad Radiance 2000; BioRad, Hemel Hempsted, UK) and Z-series were merged using Lasersharp (BioRad) software. 


\section{Data analysis}

All non-SuperArray data were collected in Microsoft Excel and all statistical analyses and graphs were produced using GraphPad Prism. Quantification of cytoplasmic and nuclear Ube1/TOPRO3 fluorescence was undertaken on confocal micrographs captured using identical microscope settings between images and specimens. No image manipulation was undertaken before quantification using standard fluorescence intensity tools in Image $\mathrm{J}$ software. Images were prepared for presentation in Adobe Photoshop.

\section{Abbreviations}

eGFP, enhanced green fluorescent protein; MTT, 3-(4,5dimethylthiazolyl-2)-2,5-diphenyltetrazolium bromide; NAD, nicotinamide adenine dinucleotide; Nmnat1, nicotinamide mononucleotide adenylyltransferase 1; PBS, phosphatebuffered saline; PCR, polymerase chain reaction; Pttg1, pituitary tumor transforming gene 1; STI1, stress-induced phosphoprotein 1; Ube1, ubiquitin-activating enzyme E1; Ube4b, ubiquitination factor $\mathrm{E} 4 \mathrm{~B}$; VCP, valosin-containing protein; $W l d^{s}$, slow Wallerian degeneration.

\section{Authors' contributions}

TMW and THG conceived, designed and coordinated the study, undertook the genomic, proteomic and immunocytochemical assays and drafted the manuscript. HNP, SRJ, and CJM carried out the cell proliferation assays. All authors read and approved the final manuscript.

\section{Acknowledgements}

The authors would like to thank Sara Meredith and Dr Emma Perkins for assistance with some of the immunocytochemical experiments, Derek Thomson for assistance with animal breeding, Dr N Cashman for providing NSC34 cells, and Dr Simon Parson and members of the Gillingwater and Parson laboratories for helpful discussion and comments on the manuscript. Flavopiridol was kindly provided by Sanofi-Aventis Pharmaceuticals Inc. through an agreement with the National Cancer Institute (Rockville, MD, USA). This work was supported by grants from the BBSRC (THG/ TMW), Medical Research Scotland (THG), and the MRC (HNP/CJM).

\section{References}

I. Gillingwater TH, Ribchester RR: Compartmental neurodegeneration and synaptic plasticity in the Wlds mutant mouse. J Physiol 2001, 534:627-639.

2. Raff MC, Whitmore AV, Finn JT: Axonal destruction and neurodegeneration. Science 2002, 296:868-87I.

3. Coleman MP, Perry VH: Axon pathology in neurological disease: a neglected therapeutic target. Trends Neurosci 2002, 25:532-537.

4. Wishart TM, Parson SH, Gillingwater TH: Synaptic vulnerability in neurodegenerative disease. I Neuropathol Exp Neurol 2006, 65:733-739.

5. Lunn ER, Perry VH, Brown MC, Rosen H, Gordon S: Absence of Wallerian degeneration does not hinder regeneration in peripheral nerve. Eur J Neurosci 1989, I:27-33.

6. Ludwin SK, Bisby MA: Delayed Wallerian degeneration in the central nervous system of Ola mice: an ultrastructural study. | Neurol Sci 1992, 109: |40-147.

7. Ribchester RR, Tsao JW, Barry JA, Asgari-Jirhandeh N, Perry VH, Brown MC: Persistence of neuromuscular junctions after axotomy in mice with slow Wallerian degeneration (C57BI/ WIds). Eur J Neurosci 1995, 7:164l-1650.

8. Samsam M, Mi W, Wessig C, Zielasek J, Toyka KV, Coleman MP, Martini R: The WIds mutation delays robust loss of motor and sensory axons in a genetic model for myelin-related axonopathy. J Neurosci 2003, 23:2833-2839.

9. Ferri A, Sanes JR, Coleman MP, Cunningham JM, Kato AC: Inhibiting axon degeneration and synapse loss attenuates apoptosis and disease progression in a mouse model of motoneuron disease. Curr Biol 2003, 13:669-673.

10. Sajadi A, Schneider BL, Aebischer P: WIds-mediated protection of dopaminergic fibers in an animal model of Parkinson disease. Curr Biol 2004, 14:326-330.

II. Mi W, Beirowski B, Gillingwater TH, Adalbert R, Wagner D, Grumme D, Osaka H, Conforti L, Arnhold S, Addicks K, Wada K, Ribchester RR, Coleman MP: The slow Wallerian degeneration gene, Wids, inhibits axonal spheroid pathology in gracile axonal dystrophy mice. Brain 2005, I 28:405-4I6.

12. Gillingwater TH, Ingham CA, Parry KE, Wright AK, Haley JE, Wishart TM, Arbuthnott GW, Ribchester RR: Delayed synaptic degeneration in the CNS of WIds mice after cortical lesion. Brain 2006, I 29: I546-I556.

13. Conforti L, Tarlton A, Mack TG, Mi W, Buckmaster EA, Wagner D, Perry VH, Coleman MP: A Ufd2/D4Cole le chimeric protein and overexpression of Rbp7 in the slow Wallerian degeneration (WIdS) mouse. Proc Natl Acad Sci USA 2000, 97: I I 377- I I 382.

14. Mack TGA, Reiner M, Beirowski B, Mi W, Emanuelli M, Wagner D, Thomason D, Gillingwater THG, Gourt F, Conforti L, Fernando FS, Tarlton A, Andressen C, Addicks K, Magni G, Ribchester RR, Perry $\mathrm{VH}$, Coleman MP: Wallerian degeneration of injured axons and synapses is delayed by a Ube4b/Nmnat chimeric gene. Nat Neurosci 200I, 4:I 199-I206.

15. Adalbert R, Gillingwater TH, Haley JE, Bridge K, Beirowski B, Berek L, Wagner D, Grumme D, Thomson D, Celik A, Addicks K, Ribchester RR, Coleman MP: A rat model of slow Wallerian degeneration (WIds) with improved preservation of neuromuscular synapses. Eur J Neurosci 2005, 2 I:27 I-277.

16. MacDonald JM, Beach MG, Porpiglia E, Sheehan AE, Watts RJ, Freeman MR: The Drosophila cell corpse engulfment receptor Draper mediates glial clearance of severed axons. Neuron 2006, 50:869-88I.

17. Deckwerth TL, Johnson EM: Neurites can remain viable after the destruction of the neuronal soma by programmed cell death. Dev Biol 1994, 165:63-72.

18. Adalbert R, Nogradi A, Szabo A, Coleman MP: The slow Wallerian degeneration gene in vivo protects motor axons but not their cell bodies after avulsion and neonatal axotomy. Eur J Neurosci 2006, 24:2I63-2168.

19. Wang AL, Yuan M, Neufeld AH: Degeneration of neuronal cell bodies following axonal injury in WIds mice. J Neurosci Res 2006, 84: $1799-1807$.

20. Fang C, Bernardes-Silva M, Coleman MP, Perry VH: The cellular distribution of the WIds chimeric protein and its constituent proteins in the CNS. Neuroscience 2005, I35: I I07- I I I8.

21. Gillingwater TH, Haley JE, Ribchester RR, Horsburgh K: Neuroprotection after transient global cerebral ischaemia in WIds Mutant Mice. J Cereb Blood Flow Metab 2004, 24:62-66.

22. Gillingwater TH, Wishart TM, Chen PE, Haley JE, Robertson K, MacDonald SH, Middleton S, Wawrowski K, Shipston MJ, Melmed S, Wyllie DJ, Skehel PA, Coleman MP, Ribchester RR: The neuroprotective WIdS gene regulates expression of PTTG I and erythroid differentiation regulator I-like gene in mice and human cells. Hum Mol Genet 2006, I 5:625-635.

23. Araki T, Sasaki Y, Milbrandt J: Increased nuclear NAD biosynthesis and SIRTI activation prevent axonal degeneration. Science 2004, 305:1010-1013.

24. Wang J, Zhai Q, Chen Y, Lin E, Gu W, McBurney MW, He Z: A local mechanism mediates NAD-dependent protection of axon degeneration. J Cell Biol 2005, I 70:349-355.

25. Sasaki Y, Araki T, Milbrandt J: Stimulation of nicotinamide adenine dinucleotide biosynthetic pathways delays axonal degeneration after axotomy. J Neurosci 2006, 26:8484-849l.

26. Conforti L, Fang G, Beirowski B, Wang MS, Sorci L, Asress S, Adalbert R, Silva A, Bridge K, Huang XP, Magni G, Glass JD, Coleman MP: NAD $^{+}$and axon degeneration revisited: Nmnat l cannot substitute for WIdS to delay Wallerian degeneration. Cell Death Differ 2007, 14:1 16-127.

27. Watanabe M, Tsukiyama T, Hatakeyama S: Protection of vincris- 
tine-induced neuropathy by WId(S) expression and the independence of the activity of Nmnatl. Neurosci Lett 2006, 41 I:228-232.

28. Laser H, Conforti L, Morreale G, Mack TG, Heyer M, Haley JE, Wishart TM, Beirowski B, Walker SA, Haase G, Celik A, Adalbert R, Wagner D, Grumme D, Ribchester RR, Plomann M, Coleman MP: The slow Wallerian degeneration protein, WIdS, binds directly to VCP/p97 and partially redistributes it within the nucleus. Mol Biol Cell 2006, I 7: I075- 1084.

29. Simonin $Y$, Ferrer-Alcon M, Ferri A, Kato AC: The neuroprotective effects of the WIdS gene are correlated with proteasome expression rather than apoptosis. Eur J Neurosci 2007, 25:2269-2274

30. Simonin Y, Perrin FE, Kato AC: Axonal involvement in the WIds neuroprotective effect: analysis of pure motoneurons in a mouse model protected from motor neuron disease at a pre-symptomatic age. J Neurochem 2007, I 0 I:530-542.

31. Wishart TM, Paterson JM, Short DM, Meredith S, Robertson KA, Sutherland C, Cousin MA, Dutia MB, Gillingwater TH: Differential proteomics analysis of synaptic proteins identifies potential cellular targets and protein mediators of synaptic neuroprotection conferred by the slow Wallerian degeneration (WIds) gene. Mol Cell Proteomics 2007, 6: I3 I8-1330.

32. Tong $Y$, Tan $Y$, Zhou C, Melmed S: Pituitary tumor transforming gene interacts with $\mathrm{SpI}$ to modulate GI/S cell phase transition. Oncogene 2007, 26:5596-5605.

33. Jin J, Li X, Gygi SP, Harper JW: Dual EI activation systems for ubiquitin differentially regulate $\mathrm{E} 2$ enzyme charging. Nature 2007, 447: II35-II38.

34. Lee TV, Ding T, Chen Z, Rajendran V, Scherr H, Lackey M, Bolduc C, Bergmann A: The EI ubiquitin-activating enzyme Ubal in Drosophila controls apoptosis autonomously and tissue growth non-autonomously. Development 2008, I35:43-52.

35. Sudha T, Tsuji H, Sameshima M, Matsuda Y, Kaneda S, Nagai Y, Yamao $\mathrm{F}$, Seno T: Abnormal integrity of the nucleolus associated with cell cycle arrest owing to the temperature-sensitive ubiquitin-activating enzyme EI. Chromosome Res 1995, 3:I I5-123.

36. Stephen AG, Trausch-Azar JS, Ciechanover A, Schwartz AL: The ubiquitin-activating enzyme $\mathrm{EI}$ is phosphorylated and localized to the nucleus in a cell cycle-dependent manner. J Biol Chem 1996, 27I:I5608-156I4.

37. Madeo F, Schlauer J, Zischka H, Mecke D, Fröhlich KU: Tyrosine phosphorylation regulates cell cycle-dependent nuclear localization of Cdc48p. Mol Biol Cell 1998, 9: |3 |- |4|

38. Brachmann CB, Sherman JM, Devine SE, Cameron EE, Pillus L, Boeke JD: The SIR2 gene family, conserved from bacteria to humans, functions in silencing, cell cycle progression, and chromosome stability. Genes Dev 1995, 9:2888-2902.

39. Haigis MC, Guarente LP: Mammalian sirtuins: emerging roles in physiology, aging, and calorie restriction. Genes Dev 2006, 20:2913-2921.

40. Sasaki T, Maier B, Bartke A, Scrable H: Progressive loss of SIRT I with cell cycle withdrawal. Aging Cell 2006, 5:4I 3-422.

4I. Herrup K, Yang Y: Cell cycle regulation in the postmitotic neuron: oxymoron or new biology? Nat Rev Neurosci 2007, 8:368-378.

42. Vincent I, Pae $\mathrm{Cl}$, Hallows JL: The cell cycle and human neurodegenerative disease. Prog Cell Cycle Res 2003, 5:31-4I.

43. Klein JA, Ackerman SL: Oxidative stress, cell cycle, and neurodegeneration. J Clin Invest 2003, I I I:785-793.

44. Khurana V, Feany MB: Connecting cell-cycle activation to neurodegeneration in Drosophila. Biochim Biophys Acta 2007, I 772:446-456.

45. Ranganathan S, Bowser R: Alterations in $\mathbf{G}$, to $\mathbf{S}$ phase cell-cycle regulators during amyotrophic lateral sclerosis. Am J Pathol 2003, 1 62:823-835.

46. Vincent I, Rosado M, Davies P: Mitotic mechanisms in Alzheimer's disease? J Cell Biol 1996, I32:413-425.

47. Love S: Neuronal expression of cell cycle-related proteins after brain ischaemia in man. Neurosci Lett 2003, 353:29-32.

48. Di Giovanni S, Movsesyan V, Ahmed F, Cernak I, Schinelli S, Stoica B, Faden Al: Cell cycle inhibition provides neuroprotection and reduces glial proliferation and scar formation after traumatic brain injury. Proc Natl Acad Sci USA 2005, I 02:8333-8338.

49. Wang F, Corbett D, Osuga H, Osuga S, Ikeda JE, Slack RS, Hogan MJ, Hakim AM, Park DS: Inhibition of cyclin-dependent kinases improves CAI neuronal survival and behavioral performance after global ischemia in the rat. J Cereb Blood Flow Metab
2002, 22:17|-182.

50. Peng GH, Ahmad O, Ahmad F, Liu J, Chen S: The photoreceptorspecific nuclear receptor Nr2e3 interacts with Crx and exerts opposing effects on the transcription of rod versus cone genes. Hum Mol Genet 2005, I 4:747-764.

5I. Croxen R, Hatton C, Shelley C, Brydson M, Chauplannaz G, Oosterhuis H, Vincent A, Newsom-Davis J, Colqhoun D, Beeson D: Recessive inheritance and variable penetrance of slow-channel congenital myasthenic syndromes. Neurology 2002, 59:162-168.

52. Lang B, Pinto A, Giovannini F, Newsom-Davis J, Vincent A: Pathogenic autoantibodies in the lambert-eaton myasthenic syndrome. Ann NY Acad Sci 2003, 998:187-195.

53. Joo HY, Zhai L, Yang C, Nie S, Erdjument-Bromage H, Tempest $P$, Chang C, Wang H: Regulation of cell cycle progression and gene expression by H2A deubiquitination. Nature 2007, 449: $1068-1072$

54. Barber CM, Turner FB, Wang Y, Hagstrom K, Taverna SD, Mollah S, Uberheide B, Meyer BJ, Hunt DF, Cheung P, Allis CD: The enhancement of histone $\mathrm{H} 4$ and $\mathrm{H} 2 \mathrm{~A}$ serine I phosphorylation during mitosis and S-phase is evolutionarily conserved. Chromosoma 2004, I I 2:360-37I.

55. Boelaert K, Smith VE, Stratford AL, Kogai T, Tannahill LA, Watkinson JC, Eggo MC, Franklyn JA, McCabe CJ: PTTG and PBF repress the human sodium iodide symporter. Oncogene 2007, 26:4344-4356.

56. Spinette S, Lengauer C, Mahoney JA, Jallepalli PV, Wang Z, CasciolaRosen L, Rosen A: Ufd2, a novel autoantigen in scleroderma, regulates sister chromatid separation. Cell Cycle 2004, 3:1638-1644.

57. Yu R, Lu W, Chen J, McCabe CJ, Melmed S: Overexpressed pituitary tumor-transforming gene causes aneuploidy in live human cells. Endocrinology 2003, I44:499|-4998.

58. Yang $Y$, Herrup $\mathrm{K}$ : Cell division in the CNS: protective response or lethal event in post-mitotic neurons? Biochim Biophys Acta 2007, I 772:457-466.

59. Krantic S, Mechawar N, Reix S, Quirion R: Molecular basis of programmed cell death involved in neurodegeneration. Trends Neurosci 2005, 28:670-676.

60. Chong ZZ, Li F, Maiese K: Attempted cell cycle induction in post-mitotic neurons occurs in early and late apoptotic programs through Rb, E2FI, and caspase 3. Curr Neurovasc Res 2006, 3:25-39.

61. Wang Q, Song C, Li CC: Molecular perspectives on p97-VCP: progress in understanding its structure and diverse biological functions. J Struct Biol 2004, I 46:44-57.

62. Kaneko C, Hatakeyama S, Matsumoto M, Yada M, Nakayama K, Nakeyama KI: Characterization of the mouse gene for the $\mathbf{U}$ box-type ubiquitin ligase UFD2a. Biochem Biophys Res Commun 2003, 300:297-304.

63. Zhang H, Wang Q, Kajino K, Greene MI: VCP, a weak ATPase involved in multiple cellular events, interacts physically with BRCAI in the nucleus of living cells. DNA Cell Biol 2000, 19:253-263.

64. McLaughlin B, Hartnett KA, Erhardt JA, Legos JJ, White RF, Barone FC, Aizenman E: Caspase 3 activation is essential for neuroprotection in preconditioning. Proc Natl Acad Sci USA 2003, 100:715-720.

65. Mattson MP, Cheng A: Neurohormetic phytochemicals: Lowdose toxins that induce adaptive neuronal stress responses. Trends Neurosci 2006, 29:632-639.

66. Gáspár T, Kis B, Snipes JA, Lenzsér G, Mayanagi K, Bari F, Busija DW: Transient glucose and amino acid deprivation induces delayed preconditioning in cultured rat cortical neurons. J Neurochem 2006, 98:555-565.

67. Obrenovitch TP: Molecular physiology of preconditioninginduced brain tolerance to ischemia. Physiol Rev 2008, 88:2 II-247.

68. Zhai RG, Zhang F, Hiesinger PR, Cao Y, Hauter CM, Bellen HJ: NAD synthase NMNAT acts as a chaperone to protect against neurodegeneration. Nature 2008, 452:887-89l.

69. Press C, Milbrandt J: Nmnat delays axonal degeneration caused by mitochondrial and oxidative stress. J Neurosci 2008, 28:486 I-487I.

70. Lopes MH, Hajj GN, Muras AG, Mancini GL, Castro RM, Ribeiro KC, Brentani RR, Linden R, Martins VR: Interaction of cellular prion and stress-inducible protein I promotes neuritogenesis and neuroprotection by distinct signaling pathways. I Neurosci 2005, 25: I 1330-1 |339. 
7I. Erlich RB, Kahn SA, Lima FR, Muras AG, Martins RA, Linden R, Chiarini LB, Martins VR, Moura Neto V: STII promotes glioma proliferation through MAPK and PI3K pathways. Glia 2007, 55:1690-1698.

72. Arruda-Carvalho M, Njaine B, Silveira MS, Linden R, Chiarini LB: Hop/STII modulates retinal proliferation and cell death independent of PrPC. Biochem Biophys Res Commun 2007, $361: 474-480$.

73. Cashman NR, Durham HD, Blusztajn JK, Oda K, Tabira T, Shaw IT, Dahrouge S, Antel JP: Neuroblastoma $x$ spinal cord (NSC) hybrid cell lines resemble developing motor neurons. Dev Dyn 1992, 194:209-221.

74. Raw array data [http://www.cip.ed.ac.uk/members/HRB/gillingwa ter/index.htm] 